\title{
Abstracts from the Conjoint Annual Meeting of L'Association des pneumologues de la province de Québec and le Réseau en santé respiratoire du FRSQ
}

\begin{abstract}
1
BRONCHIAL FIBROBLASTS MODULATE CD4+ ${ }^{+}$T CELLS

PHENOTYPE TOWARDS TH17 IN ASTHMA

L Loubaki, S Plante, E Jacques, J Chakir

Centre Recherche, Institut Universitaire de Cardiologie et de

Pneumologie de Québec, Québec, QC

BACKGROUND: In asthma, $\mathrm{CD} 4^{+} \mathrm{T}$ cells are selectively recruited into the bronchial mucosa. CD4 ${ }^{+} \mathrm{T}$ cells consist of different subsets that express lineage-specific transcription factors and play different roles either in initiating and supporting the development of immune response, but also in orchestrating and regulating them.

OBJECTIVES: The aim of our study was to evaluate the effect of T cellsbronchial fibroblasts interaction on $\mathrm{CD}^{+} \mathrm{T}$ cell phenotype.

METHODS: Human bronchial fibroblasts were isolated from mild steroid naïve asthmatics and nonatopic healthy controls. $\mathrm{CD} 4^{+} \mathrm{T}$ cells were purified from the peripheral blood of healthy and asthmatic subjects. Co-culture of confluent healthy (HF) or asthmatic bronchial fibroblasts (AF) with T cells were performed. CD4 ${ }^{+} \mathrm{T}$ cell total RNA was purified and GATA-3, Foxp3 and RORc expression was detected by quantitative PCR. Th17 (IL-17,IL-22) lineage-specific cytokines profile were also evaluated.

RESULTS: Co-culture of $T$ cells with bronchial fibroblasts significantly stimulated RORc in asthmatic T cells only, whereas Foxp3 and GATA-3 were not affected in both asthmatic and healthy T cells. IL-6 and IL-23 expression either by AF and HF were also significantly increased by the coculture when, TGF- $\beta$ expression was not affected. In CD4 ${ }^{+} \mathrm{T}$ cells, IL-17 and IL-22, Th17 lineage-specific cytokines were significantly increased by the coculture with AF.

CONCLUSION: Interaction between bronchial fibroblasts and $\mathrm{T}$ cells seems to specifically promote Th17 cells profile in asthma. These results suggest that cellular interactions particularly between $\mathrm{T}$ cells and fibroblasts may play a pivotal role in the regulation of the inflammatory response in asthma.
\end{abstract}

\section{2}

MUSCULAR DYSTROPHY: MOLECULAR MECHANICS OF MYOSIN IN THE MDX MOUSE DIAPHRAGM

G Bates, A-M Lauzon.

Meakins-Christie Laboratories, McGill University, Montreal, QC

Duchenne muscular dystrophy (DMD) is an inherited X-linked, lethal disorder in humans. It is caused by defects in the dystrophin gene which usually leads to death from either respiratory or cardiac muscle failure in the 2 nd or 3 rd decade of life. It is known that the lack of dystrophin predisposes muscle cell membranes to mechanical damage; however, the contractile proteins themselves may also play an important role in the pathogenesis of muscle weakness. To explore this possibility, myosin from the diaphragms of control (C57BL/10) and $\mathrm{mdx}(\mathrm{C} 57 \mathrm{Bl} / 10$; murine model of DMD lacking dystrophin) mice were purified for use in the in vitro motility assay. This assay, briefly, consists in observing the movement of fluorescently labeled actin filaments as they are propelled by myosin molecules randomly adhered to a microscope coverslip. Three-month-old mice were used since it has been previously shown at the muscle strip level that, at this age, force is impaired in the mdx diaphragm. To date, the velocity of actin propulsion (vmax) has been quantified and an increase for the $\mathrm{mdx}$ myosin $(1.75 \mu \mathrm{m} / \mathrm{s} \pm 0.131 ;$ mean \pm sem, $\mathrm{n}=4)$ compared to control $(1.305 \mu \mathrm{m} / \mathrm{s} \pm 0.104 ; \mathrm{p}<0.0005, \mathrm{n}=4)$ was found. Relative force generation for the two types of myosin is also being quantified using two different force assays. The first, the $\alpha$-actinin assay, is identical to the motility assay except that $\alpha$-actinin is added to induce a load on the actin filaments. Relative force is inferred based on the concentration of $\alpha$-actinin required to completely inhibit motility in both myosin samples. The second assay, the mixed assay, will involve performing the motility with different concentrations of a fast and slow myosin (control and mdx myosins in this case) mixed together to get a concentration vs. vmax relationship whose curvature depends on the relative force of the two types of myosin. Supported by: NSERC, FRSQ, MUHC

\section{3}

DIFFERENTIAL EXPRESSION OF CD200 AND CHEMOKINE PROFILE IN BRONCHIAL EPITHELIAL CELLS OF NORMAL AND ALLERGEN-CHALLENGED ANIMALS

Jean-François Lauzon-Joset, Véronique Turmel, Elyse Y Bissonnette Centre de recherche de I'Institut universitaire de cardiologie et de pneumologie de Québec, Université Laval, Québec, QC

INTRODUCTION: Epithelial cells play a central role in lung homeostasis. They create a physical barrier and participate in lung immune response and remodelling by recruiting immune cells and releasing a large number of mediators. CD200, an immunomodulatory molecule involved in the inhibition of myeloid cell activation, is also expressed by epithelial cells. In order to better understand their role and the modification of their phenotype in the asthmatic cascade, bronchial epithelial cells were isolated from naïve (NBE), sensitized (SBE), and allergen-challenged ( $\mathrm{ABE}$ ) rats.

METHODS: Mediator profile was investigated in supernatants of cells cultured for $24 \mathrm{~h}$ using ELISA, whereas the expression of proteins of the tight junction apparatus was determined by western. Presence of CD200 on cell membrane was also investigated using FACS analysis.

RESULTS: ABE produced less inflammatory cytokines (IL-6, TNF and IL-1alpha), but more active TGF-beta and chemokines (MCP-1 and eotaxin-1) compared with NBE and SBE. Interestingly, SBE showed an intermediate chemokine profile. ABE showed a reduce expression of adherence junction proteins (E-Cadherin and Zonula Occludens-1), but an overexpression of Claudin-1, a tight junction protein, compared with NBE. SBE expressed low levels of all three proteins. Strikingly, CD200 expression was restricted to NBE.

CONCLUSION: These results suggest that epithelial cells maintain their distinct phenotype in vitro and that sensitization was sufficient to disturb normal epithelial cell functions. This is an attractive model to further investigate epithelial cell functions and regulation in the asthmatic cascade.

\section{4}

CARACTÉRISATION DE L'EXPRESSION DES ISOFORMES DE L'ARGINASE DANS UN MODÈLE ÉQUIN DE MALADIE RESPIRATOIRE ALLERGIQUE

A Lavoie-Lamoureux, JP Lavoie

Faculty de Médecine Vétérinaire, Univesité de Montréal, Montréal, QC CONTEXTE: L'arginase (arg) I et II pourraient contribuer à la physiopathologie des maladies respiratoires chroniques en limitant la relaxation musculaire, favorisant la synthèse de collagène ainsi qu'en régulant la réponse immunitaire. Puisque des différences inter-espèces existent quant au profile d'expression des arg I et II par les leucocytes, nous avons caractérisé leur expression dans un modèle équin de maladie respiratoire allergique.

MÉTHODES: L'expression génique et protéique de l'arg I et II a été étudiée par RT-PCR et immunobuvardage, respectivement, dans les 
neutrophiles périphériques, les cellules de LBA et dans le poumon périphérique de chevaux atteints du souffle et contrôles. L'activité enzymatique a été quantifiée à l'aide d'un kit commercial. Des extraits de foie et de rein de cheval ainsi que des neutrophiles humains ont été utilisés comme contrôles positifs.

RÉSULTATS : L'arg I n'a pas été détectée dans les neutrophiles périphériques ou pulmonaires équins, sans effet supplémentaire d'une stimulation avec l'IL-4 (Th2, 5 ou 18h). Toutefois, l'arg I était détectée préférentiellement dans les poumons des chevaux malades. L'arg II était fortement exprimée dans les neutrophiles équins et possédait une activité enzymatique. L'exposition antigénique a augmenté l'expression pulmonaire d'arg II dans les deux groupes, mais était significativement supérieure et associée à la résistance pulmonaire chez les chevaux atteints du souffle.

CONCLUSIONS : L'expression d'arg II par les neutrophiles équins leur confère une contribution potentielle au caractère chronique de l'inflammation et au remodelage tissulaire chez les chevaux atteints du souffle.

\section{5}

\section{INTERLEUKIN-13 PROMOTES A CONTRACTILE PHENOTYPE IN HUMAN AIRWAYS SMOOTH MUSCLE CELLS}

PA Risse ${ }^{1}$, F Suarez ${ }^{2}$, T Jo ${ }^{1}$, P Ferraro ${ }^{3}$, P Grütter ${ }^{2}$, J G Martin ${ }^{1}$ ${ }^{1}$ Meakins-Christie Laboratories, McGill University; ${ }^{2}$ Department of Physics, Nanoscience \& Scanning Probe Microscopy Group, McGill University; Montréal and Notre Dame Hospital, Université de Montréal, Montréal, QC

BACKGROUND: Airway smooth muscle (ASM) plays a central role in several pathophysiological features of asthma such as bronchial hyperresponsiveness (BHR) and airway remodeling. Increased contractility and proliferation, respectively, can contribute to these features. Interleukin (IL) -13 is a Th2 cytokine described as an important mediator in asthma. IL-13 induces calcium sensitization, eotaxin secretion and promotes leukotriene (LT)-D4-induced proliferation of ASM.

HYPOTHESIS: IL-13 promotes ASM maturation towards a pro-contractile phenotype associated with a decrease in proliferation and an increase in contractile protein expression.

METHODS: Primary human ASM cells (passage 2 to 5) were cultured. The effect of IL-13 $(3,10$ or $30 \mathrm{ng} / \mathrm{ml})$ was studied in a proliferative $(10 \%$ FBS) or a starvation ( $0.4 \%$ FBS) environment. ASM phenotype was investigated using proliferation assay, atomic force microscopy (AFM) and contractile protein expression.

RESULTS: IL-13 induced a concentration-dependent inhibition of ASM cell proliferation ( $20 \%$ decrease of BrdU positive cells at $3 \mathrm{ng} / \mathrm{ml}, \mathrm{p}<0.05$ ). This was not reversed with leflunomide, a Stat6 inhibitor, or SecinH3, an insulin receptor substrate protein (IRS) phosphorylation inhibitor. AFM measurements showed that IL-13 enhanced histamine-induced increase of ASM stiffness without affecting baseline values. Expression of calponin, smooth muscle $\alpha$-actin and the cys-LT1 receptor mRNA were increased in the presence of IL-13.

CONCLUSION: These results demonstrate that IL-13 promotes human ASM towards a pro-contractile phenotype and may contribute to BHR in asthmatic patients.

\section{6}

\section{THE ROLE OF ALUM IN INDUCING A TH17 RESPONSE IN AN OVA MURINE MODEL OF ALLERGIC ASTHMA}

\section{E Nakada, J Shan, M Kinyanjui, E Fixman}

Meakins-Christie Laboratories, McGill University, Montreal, QC

BACKGROUND: The role of Th17 cells and IL-17 in regulating allergic airways disease in murine models is poorly understood. Alum is commonly used as an adjuvant in models of allergic airways disease to promote Th2 responses, although the effect of alum on induction of Th17 cells is unclear. We have quantified Th17 cell induction and IL-17 production in mice sensitized intraperitoneally (ip) to ovalbumin (OVA) \pm alum.

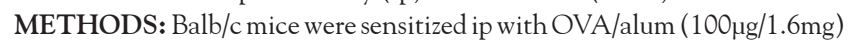

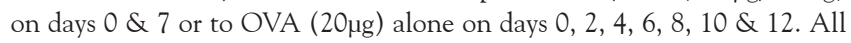
mice were challenged intranasally with OVA $(50 \mu \mathrm{g})$ on days 28-30 and sacrificed on day 31. Bronchoalveolar lavage fluid (BALF) was collected and splenocytes were cultured with OVA for $4 \mathrm{~d}$ in order to quantify Th1, Th2, \& Th17 cytokines by ELISA and the frequency of CD4+CCR6+ Th17 cells by FACS. BALF cell counts and OVA-specific IgE were also quantified.

RESULTS: Both i.p. OVA groups had similar BALF inflammatory cell profiles. The percentage of CCR6+ cells within the CD4+ population was significantly lower in the OVA/alum group. Within the CD4+ splenocyte population at $4 \mathrm{~d}$ of culture, the percentage of CCR6+ cells was higher in mice sensitized to OVA in the absence of alum. There was a trend for splenocytes from mice sensitized to OVA without alum to produce greater amounts of IL-4, IL-13, IFN- $\alpha$, IL-17 \& IL-17F, though IL-17 \& IL-17F in BALF did not differ between groups. OVA specific IgE was detectable in the sera of both OVA groups.

CONCLUSION: Our data suggest that the presence of alum during ip OVA sensitization is not necessary to promote Th2 dependent airway inflammation and may actually attenuate the Th17 response.

\section{7}

\section{EFFECTOR FUNCTION OF CD34 ${ }^{+}$HEMOPOIETIC PROGENITOR CELLS IN ALLERGIC INFLAMMATION}

Zoulfia Allakhverdi ${ }^{1}$, Michael R Comeau ${ }^{2}$, Dirk E Smith ${ }^{2}$, Dean Toy ${ }^{2}$, Leandra M. Endam ${ }^{3}$, Martin Desrosier ${ }^{3}$, Karen J Howie ${ }^{4}$, Judah A Denburg ${ }^{4}$, Gail M Gauvreau ${ }^{4}$, Guy Delespesse ${ }^{1}$

${ }^{1}$ Notre-Dame Hospital, CHUM Research Centre, Montreal, QC;

${ }^{2}$ Inflammation Research, Amgen Inc, Seattle, USA; ${ }^{3}$ Department of Otorhinolaryngology, CHUM, Hotel-Dieu Hospital, Montreal, QC; ${ }^{4}$ Asthma Research Group, McMaster University, Hamilton, ON

PURPOSE: In allergic diseases, the bone marrow releases increased numbers of $\mathrm{CD} 34^{+}$progenitor cells that migrate to the site of allergic inflammation where they differentiate into tissue dwelling and classical effector cells of allergy, such as mast cells, eosinophils and basophils. We here provide evidence that in addition to being progenitors, the blood CD34 ${ }^{+}$cells may display a robust proinflammatory activity and may thereby contribute to the pathogenesis of allergic diseases.

METHODS: Highly purified neonatal or adult blood CD34 ${ }^{+}$cells were examined for the expression of TSLP and IL-33 receptors and for their response to these cytokines as well as to supernatants of primary small airway epithelial cells and nasal explants from rhinosinusitis and control subjects. Sputum of asthmatic patients was examined before and after allergen inhalation for the presence of IL-5 and IL-13 containing CD $34^{+}$cells. FINDINGS: Circulating CD $34^{+}$cells expressed receptors for TSLP and IL-33 and responded to these cytokines by rapidly releasing high levels of proinflammatory Th2-like cytokines and chemokines. These cells were activated in a TSLP-dependent manner by the supernatant fluids from activated primary human small airway epithelial cells and from nasal explants of chronic rhinosinusitis patients. Moreover, activated CD34 ${ }^{+}$ cells containing IL-5 and IL-13 could be detected in the sputum of allergic asthmatic individuals, with numbers increasing in response to specific allergen inhalation challenge.

DELIVERABLES: Blood CD $34^{+}$cells in addition to being progenitors act as proinflammatory effector cells by themselves and may thereby contribute to the pathogenesis of allergic diseases.

RELEVANCE: The effect of current anti-allergic treatment on the proinflammatory activity of $\mathrm{CD} 34^{+}$cells should be taken into account and these cells could be considered as target for the development of novel therapeutic approaches for atopic diseases. 
8

DOWN-REGULATION OF EPITHELIAL TOLL-LIKE RECEPTOR 4 IN ASTHMA AND RHINITIS: A POSSIBLE ROLE FOR GATA-3

Préfontaine $\mathrm{D}^{1}$, Al-Ramli $\mathrm{W}^{1}$, Mogas $\mathrm{AK}^{1}$, Semlali $\mathrm{A}^{2}$, Chakir $\mathrm{J}^{2}$, Lavigne $\mathrm{F}^{3}$, Frenkiel $\mathrm{S}^{4}$, Hamid $\mathrm{Q}^{1}$

${ }^{1}$ Meakins-Christie Labs, McGill University, Montreal; ${ }^{2}$ Faculty of Medicine, Laval University, Québec; ${ }^{3}$ Hotel-Dieu de Montréal \& Notre-Dame Hospital; ${ }^{4} J e w i s h$ General Hospital-Sir Mortimer B Davis, Montreal, QC

INTRODUCTION: In asthma and rhinitis, airway epithelial cells display a pro-inflammatory phenotype and respond to various stimuli. The role of bacterial lipopolysaccharide (LPS) in asthma exacerbations and inflammation remains controversial. In our study, we asked the question whether on-going allergic disease of the airways regulates Toll-like receptor 4 (TLR-4) expression by the epithelium, and hypothesized that the transcription factor GATA-3 is involved.

METHODS: Nasal mucosa biopsies were obtained from allergic rhinitis and non-allergic adults. Bronchial epithelial cells were also isolated from asthmatic and controls. Primary normal bronchial epithelial cells and the BEAS-2B cell line were used as in vitro models. Cultured cells were transfected with GATA-3 overexpressing and siRNA vectors. Immunocytochemistry, immunofluorescence, flow cytometry and quantitative PCR served to investigate TLR-4 and GATA-3 expression.

RESULTS: TLR-4 and GATA-3 are expressed by epithelial cells of the upper airways. Rhinitis is associated with Th2-type inflammation, increased GATA-3 gene expression but reduced TLR-4. Bronchial epithelial cells from asthmatic subjects exhibited increased endogenous GATA-3 and reduced TLR-4 expression compared with cells from controls. IL-4-treated epithelial cells showed increased GATA-3 but reduced TLR-4 expression. GATA-3 siRNA vectors could augment TLR-4 expression, whereas GATA-3 overexpression had limited effect on TLR-4.

CONCLUSION: Airway allergic diseases are associated with reduced TLR-4 and increased GATA-3 expression in epithelial cells. GATA-3 could negatively regulate TLR-4 expression, and possibly interfere with innate immune functions.

\section{9}

\section{EFFECTS OF SENSITIZED SPLENOCYTES ON AIRWAY SMOOTH MUSCLE CONTRACTILITY}

Fairbank NJ, Nakada E, Kachmar L, Fixman E, and Lauzon A-M Meakins-Christie Laboratories, McGill University, Montreal, QC

Airway smooth muscle (ASM) from human asthmatics and animal models exhibits increased volume and velocity/extent of contraction, likely contributing to airway hyperresponsiveness (AHR). However, the mechanisms behind altered contractility are unclear. Cultured ASM cells exhibit enhanced contractility and contractile protein expression in response to a number of important cues altered in asthma, including inflammatory mediators. A main source of mediators is $\mathrm{CD}^{+} \mathrm{T}$ cells, which have been observed in the ASM layer in human biopsies and Brown Norway (BN) rats with experimental asthma and increased ASM mass. However, it is unknown how incubation with $\mathrm{CD} 4^{+} \mathrm{T}$ cells affects ASM tissue contractility, and whether the effects are dependent on T cell:ASM contact. To begin answering this question, we coincubated $\mathrm{BN}$ rat ASM tissue and sensitized splenocytes including $\mathrm{CD} 4^{+} \mathrm{T}$ cells.

HYPOTHESIS: Sensitized splenocytes enhance ASM maximal velocity of shortening $(\mathrm{Vmax})$ and contractile stress $(\mathrm{Po})$.

RESULTS AND CONCLUSIONS: Our preliminary data suggest that splenocytes increase Vmax by $51 \%$ (SE 22) at $24 \mathrm{hr}$ and $77 \%$ (SE 45) at 48 hr, but have no effect on Po ( $n=3-4)$, in agreement with data obtained by Stephens et al. from allergen-sensitized dogs. Also, using ASM and splenocytes from $\mathrm{BN}$ rats known not to develop AHR on sensitization, no increase in Vmax was observed. As it is highly likely that $\mathrm{CD}^{+} \mathrm{T}$ cells within the splenocyte population were responsible for the above increase in Vmax, we will next isolate the T cells and determine if contact between the T cells and ASM is required. The result will help to form a vital understanding of the coupling between inflammation and AHR in asthma.
10

\section{LE CRBM-0244 PRÉVIENT L'INFLAMMATION ET L'HYPERRÉACTIVITÉ DES TISSUS PULMONAIRES}

Morin $\mathrm{C}^{1,3}$, Fortin $\mathrm{S}^{1,2}$, Albadine $\mathrm{R}^{4}$, Sirois $\mathrm{M}^{5}$, Échavé $\mathrm{V}^{5}$, Rousseau $\mathrm{E}^{3}$ ${ }^{1} \mathrm{SCF}$ Pharma et ${ }^{2}$ Centre de Recherche sur les Biotechnologies Marines, Rimouski; ${ }^{3}$ Départment de Physiologie et Biophysique; ${ }^{4}$ Départment de Pathologie et ${ }^{5}$ Service de Chirurgie thoracique, FMSS, Université de Sherbrooke, Sherbrooke, QC

L'inflammation bronchique joue un rôle important dans plusieurs pathologies respiratoires. Le but du projet était d'évaluer le mode d'action et les propriétés anti-inflammatoires du CRBM-0244, un nouveau dérivé bioactif du DHA, sur les tissus pulmonaires. L'effet d'un traitement par le CRBM0244 a été évalué sur un modèle in vitro de bronchioles humaines stimulées au TNFa et dans un modèle in vivo d'asthme allergique chez le cobaye. Les résultats démontrent qu'un prétraitement au CRBM-0244 réduit l'hyperréactivité des bronchioles aux agonistes pharmacologiques $(\mathrm{MCh}$, Histamine, LTD4). Le CRBM-0244 prévient l'hypersensibilité au $\mathrm{Ca}^{2+}$ des bronchioles prétraitées au TNFa, ce qui est corrélé avec une diminution du niveau de phosphorylation et d'expression de la protéine régulatrice CPI-17. Une surexpression de la CPI-17 a été détectée par immunofluorescence dans les bronchioles traitées au TNFa et dans les biopsies de patients asthmatiques, cependant le prétraitement au CRBM-0244 prévient l'augmentation de l'expression de cette protéine régulatrice. Un traitement oral au CRBM-0244 de cobayes sensibilisés à l'ovalbumine prévient l'hyperréactivité bronchique et l'augmentation de la sensibilité au $\mathrm{Ca}^{2+}$ des myofilaments. Une réduction de l'infiltration leucocytaire et de la production de mucine a aussi été observée par immunohistochimie. De plus, ces animaux présentent une diminution de l'expression de la COX2 et de la CPI-17. Ces résultats révèlent que le CRBM-0244 est un important modulateur de l'inflammation induite, ce qui pourrait être pertinent dans l'amélioration des capacités respiratoires chez les patients atteints de pathologies respiratoires, tel que l'asthme et la MPOC.

\section{1}

\section{EFFETS DE L'INHIBITION DE L'ÉPOXYDE HYDROLASE SOLUBLE SUR LA RÉACTIVITÉ DES BRONCHIOLES HUMAINES}

Senouvo FY, Morin C, Albadine R, Sirois M, Echave V, Rousseau E Le Bilarium, Département de Physiologie et Biophysique, de Pathologie et de Chirurgie thoracique, Faculté de Médecine et des Sciences de la Santé, Université de Sherbrooke, Sherbrooke, QC

Le gène de l'époxyde hydrolase (EPHX2) est associé à la décroissance des fonctions respiratoires des patients souffrant de MPOC. Ces époxydes hydrolases solubles $(\mathrm{sEH})$ et microsomales $(\mathrm{mEH})$ hydroxylent les dérivés époxydés des acides gras poly-insaturés (PUFA), limitant ainsi la biodisponibilité des acides époxy- éícosatriénoïques (EET). Le but de l'étude est de déterminer si l'inhibition de la sEH modifierait la réactivité des muscles lisses bronchiques en augmentant la biodisponibilité des EET. Les objectifs spécifiques de l'étude sont : 1) de démontrer la différence de sensibilité aux EET dans les bronches de différents mammifères; 2) de déterminer si les EET peuvent prévenir la contraction des muscles lisses bronchiques induite par un analogue du thromboxane A2 (U- 46619) ; 3) de vérifier si les traitements avec des inhibiteurs de sEH (AUDA, t-AUCB) modifient la réactivité des bronches. Des mesures de tensions mécaniques ont été réalisées sur des bronchioles de cobayes, de souris, de rat et d'humain isolées de résection pulmonaires. Une courbe des réponses en fonction de la concentration de 14,15-EET montre que les tissus humains sont les plus sensibles aux EET. Des pré-incubations avec des concentrations cumulatives de 14,15-EET préviennent partiellement les contractions induites par un analogue du TXA2. Enfin, les traitements chroniques des bronchioles humaines avec le t- AUCB en absence et en présence de 14,15-EET exogène, démontrent une diminution significative de la réactivité des muscles lisses bronchiques. Les inhibiteurs de sEH pourraient se révéler des substrats potentiellement intéressants pour compléter une thérapie antiinflammatoire et broncho-relaxante. 
12

\section{COOPÉRATION CHRONOLOGIQUE ENTRE LE LEUCOTRIÈNE D4 ET L'INTERLEUKINE-13 DANS LA SÉCRÉTION D'ÉOTAXINE-3 PAR LES CELLULES ÉPITHÉLIALES PULMONAIRES.}

V Provost, A Langlois, F Chouinard, M Rola-Pleszczynski, N Flamand, M Laviolette

Centre de recherche de I'IUCPQ, Faculté de médecine, Université Laval, Québec; Unité d'immunologie, Département de pédiatrie, Faculté de médecine, Université de Sherbrooke, Sherbrooke, QC CONTEXTE : Les cystéinyl-leucotriènes (cysLTs) sont largement impliqués dans la physiopathologie de l'asthme et agissent via leurs récepteurs (CysLT1 et CysLT2). Toutefois, un nombre limité d'études s'est intéressé à comprendre les effets des cysLTs sur les cellules épithéliales pulmonaires. Lorsque incubées avec l'interleukine (IL)-4 et -13, les cellules épithéliales secrètent des éotaxines. Ces chimiokines induisent la migration de l'éosinophile et favorisent la biosynthèse des cysLTs. Étant donné que la biosynthèse et le relâchement des cytokines pro-inflammatoires, des éotaxines et des cysLTs surviennent relativement simultanément et au même endroit dans la muqueuse bronchique, nous croyons qu'ils régulent l'inflammation de manière coordonnée et non redondante. Nous avons donc étudié comment le LTD4 et les cytokines Th2 (IL-4 et IL-13) augmentaient la sécrétion des éotaxines par les cellules épithéliales pulmonaires.

RÉSULTATS : L'IL-4 et l'IL-13 stimulent la sécrétion des éotaxines 1, 2 et 3 par les cellules A549 après 24 h d'incubation. En contraste avec ces cytokines, le LTD4 n'induit pas la sécrétion de l'éotaxine-3. Cependant, il potentialise l'effet de l'IL-13 sur la sécrétion de l'éotaxine-3. Le LTD4 n'a aucun effet sur les cellules A549 traitées avec l'IL-4. Les cellules A549 expriment le CysLT1, mais pas le CysLT2. L'expression du CysLT1 est augmentée par l'IL-13 mais pas par l'IL-4 et/ou le LTD4. De plus, l'augmentation de l'expression du CysLT1 par l'IL-13 précède la sécrétion de l'éotaxine-3 de plusieurs heures (6 h contre $24 \mathrm{~h}$, respectivement). CONCLUSIONS : Ces résultats démontrent une coopération chronologique entre l'IL-13 et le LTD4. Premièrement, l'IL-13 augmente l'expression du CysLT1 qui est par la suite activé par le LTD4, résultant ainsi en une augmentation de la sécrétion de l'éotaxine-3 par les cellules épithéliales pulmonaires. L'éotaxine-3 peut ensuite amplifier la réponse inflammatoire en recrutant des leucocytes et en stimulant leur biosynthèse de leucotriènes. Cette boucle d'amplification positive pourrait être impliquée dans l'activation des éosinophiles des sujets asthmatiques.

\section{3}

LA BALANCE CYSTEINYL LEUCOTRIÈNES/ PROSTAGLANDINE E2 POST TRANSPLANTATION PULMONAIRE

S Ptaszynski, E O'Carroll, S Al-Mot, A Al-Rabea, C Poirier, C Bergeron CRCHUM-Hotel-Dieu, Montreal, QC

Des études récentes sur la physiopathologie des maladies pulmonaires fibrosantes suggèrent l'implication d'un déséquilibre dans la balance des eicosanoïdes. Le syndrome de bronchiolite oblitérante ( $\mathrm{SBO}$ ), une maladie fibroproliférative, est considéré comme un témoin de rejet chronique pulmonaire et est la première cause de mortalité à long terme chez les receveurs de greffe pulmonaire. Les niveaux de leucotriènes et de prostaglandines dans le poumon greffé sont inconnus à ce jour. Nous proposons qu'un déséquilibre de cysteinyl leucotriènes (CysLT) sur PGE2 existe dans le poumon greffé et pourrait être impliqué dans la pathogenèse du SBO. Afin de tester notre hypothèse nous avons quantifié les taux de CysLT et de PGE2 dans 41 échantillons de lavage bronchoalvéolaire (LBA) provenant de poumons greffés et obtenus de 30 patients différents, à des temps post greffe allant de 1 à 275 semaines. Les taux de CysLT et de PGE2 ont été quantifiés par ELISA, puis évalués dans le temps et corrélés aux donnés cliniques. Un pic de CysLT sur PGE2 a été observé à 52 semaines \pm 16 semaines post greffe. Le profil inflammatoire révèle une association entre un ratio CysLT/PGE2 > 1 et une plus grande proportion d'éosinophiles. Toutes les infections actives au cytomegalovirus ont été associées à un
CysLT/PGE2 > 1 et 7 des 8 sujets ayant des LBA répétésdémontraient une consistance à travers le temps dans leur ratio CysLT/PGE2. Nos résultats suggèrent que l'équilibre CysLT sur PGE2 se déplace en faveur des CysLT autour d'un an post greffe. Le ratio CysLT/PGE2 >1 est également corrélé avec deux facteurs de risque du SBO soit l'infection au CMV et l'éosinophilie.

\section{4}

\section{L'ENDOCANNABINOÏDE 2-ARACHIDONOYL-GLYCÉROL ACTIVE LES NEUTROPHILES HUMAINS : RÔLE DÉTERMINANT DU LTB4}

F Chouinard $^{1,3}$, J S Lefebvre ${ }^{2,3}$, C Ferland ${ }^{1,3}$, N Flamand ${ }^{1,3}$

${ }^{1}$ Centre de recherche de I'IUCPQ; ${ }^{2}$ Centre de recherche en rhumatologie et immunologie du CHUQ; ${ }^{3}$ Faculté de médecine, Université Laval, QC

CONTEXTE : Le recrutement et l'activation des neutrophiles (PMNL) dans les poumons est une étape essentielle afin d'assurer la défense de l'hôte contre les pathogènes. La migration des PMNL est dirigée par des médiateurs protéiques comme l'interleukine- 8 et/ou lipidiques comme le leucotriène (LT) B4. Les endocannabinoïdes, des médiateurs lipidiques ayant des effets reconnus sur le système nerveux central ont récemment été décrits comme affectant la réponse immune. Quoique la délétion génomique des récepteurs activés par les endocannabinoïdes augmente l'inflammation, on ignore leurs effets sur l'activation des PMNL.

OBJECTIFS : Déterminer 1) l'effet des endocannabinoïdes sur les PMNL humain; 2) les mécanismes impliqués dans les effets des endocannabinoïdes. RÉSULTATS : L'endocannabinoïde 2-arachidonoyl-glycérol (2-AG) s'est avéré un excellent activateur du PMNL en induisant plusieurs fonctions proinflammatoires de ce dernier comme la libération de peptides microbicides, la biosynthèse de LTB4 et l'activation de kinases. Le 2-AG n'était pas chimiotactique pour le PMNL mais a induit la libération d'une activité chimiotactique par ces derniers. Même si les effets des endocannabinoïdes sont souvent attribués à l'activation des récepteurs cannabinoïdes, nos résultats indiquent que tous les effets du 2-AG sur les PMNL sont attribuables à l'activation du récepteur du LTB4.

CONCLUSION : Le 2-AG active les PMNL et cette activation est la conséquence d'une biosynthèse de LTB4 de novo et d'une boucle d'amplification autocrine impliquant le récepteur du LTB4. Ces travaux dévoilent un lien fonctionnel potentiellement important entre les endocannabinoïdes et l'activation des PMNL.

\section{5}

\section{LTD4 INDUCES HB-EGF-DEPENDENT IL-8 RELEASE THROUGH EGFR ACTIVATION IN HUMAN BRONCHIAL EPITHELIAL CELLS}

T McGovern, PA Risse, K Tsuchiya, M Hassan, G Frigola,

JG Martin

Meakins-Christie Laboratories, McGill University, Montreal, QC

INTRODUCTION: Asthma is a chronic inflammatory disease associated with airway remodeling which includes epithelial cell hyperplasia and goblet cell differentiation. Following injury, epithelial cells release several inflammatory mediators that contribute to airway remodeling. Previous work has shown that LTD4 is involved in the remodeling process and significantly increases heparin-binding epidermal like growth factor (HBEGF), a ligand of epidermal growth factor receptor (EGFR), protein expression on the epithelium in a rat model of asthma. Additionally, interleukin-8 (IL-8) is a key chemokine acting to recruit neutrophils to the airways.

HYPOTHESIS: LTD4 induces IL-8 release through HB-EGF-dependent EGFR activation in human bronchial epithelial cells.

METHODS: Both primary (NHBE) and a cell line (BEAS2B) bronchial human epithelial cells were grown on an air-liquid interface and stimulated with LTD4. Concentrations of HB-EGF and IL-8 were evaluated by ELISA in cell culture supernatant following stimulation. To explore the EGFR signaling pathway, we used several inhibitors including a matrix metalloproteinase (MMP) inhibitor, GM6001, two selective EGFR tyrosine kinase inhibitors, AG1478 and PD- 153035, a selective CysLTr1 antagonist, montelukast, and an HB-EGF neutralizing antibody. 
RESULTS: Expression of the CysLT1 receptor was demonstrated by RT-PCR and immunohistochemistry. Four hours after stimulation with LTD4, concentrations of HB- EGF and IL-8 were significantly increased in supernatant. GM6001 and Montelukast blocked the LTD4-induced HB-EGF. All inhibitors/antagonists were able to decrease LTD4 induced IL-8 release.

CONCLUSION: These findings suggest LTD4 induced EGFR transactivation through the release of HB-EGF in human bronchial epithelial cells.

\section{6}

\section{LOSS OF CYSTIC FIBROSIS TRANSMEMBRANE CONDUCTANCE REGULATOR (CFTR) FUNCTION ENHANCES CYTOKINE PRODUCTION THROUGH OVER ACTIVATION OF INTRACELLULAR INFLAMMATORY SIGNALING PATHWAYS}

Leila Nattagh, Julie Bérubé, Lucie Roussel et Simon Rousseau. Meakins-Christie Laboratories, McGill University, Montreal, QC Cystic Fibrosis (CF), an autosomal recessive monogenic disorder caused by mutations of the CF transmembrane conductance regulator (CFTR), is a common fatal genetic disease affecting Caucasians. Defective CFTR function in the airway epithelium is the most life-threatening complication of $\mathrm{CF}$, characterized by mucus hypersecretion and neutrophil-dominated inflammation. As previously reported, we have observed enhanced cytokine production by human airway epithelial cells (AECs) harboring the CFTR $\Delta$ F508 mutation, the most frequent mutation found in CF, following stimulation with Pseudomonas aeruginosa. Of these cytokines, the most abundantly secreted are the pro-inflammatory mediators, interleukin(IL-) 6 and IL-8. The increased secretion of these cytokines may be contributed by the enhanced activation of the mitogen-activated protein kinase, p38 MAPK, which is known for its critical role in inflammation. Previously, we have observed a time-dependent wave of p38 MAPK activation in AECs in response to P. aeruginosa. Since the activation of the p38 MAPK can occur downstream of many bacterial receptors, including tolllike receptors (TLRs), we proceeded to test the hypothesis that $P$. aeruginosa infection leads to the activation of p38 MAPK by stimulating TLRs. We observed that blocking the activity of select TLRs followed by stimulations by $P$. aeruginosa only slightly interfered with the enhanced production of pro-inflammatory cytokines. Therefore, our data suggests that $P$. aeruginosa is capable of enhancing p38 MAPK activation via other mechanisms than TLR stimulation, leading to prolonged lung inflammation and eventual tissue destruction.

\section{7}

THE EXPRESSION OF TOLL-LIKE RECEPTORS IN CD8 ${ }^{+}$ T CELLS IN CHRONIC OBSTRUCTIVE PULMONARY DISEASE J Nadigel, D Préfontaine, D Eidelman, Q Hamid Meakins Christie Laboratories, McGill University, Montreal, QC RATIONALE: CD8 ${ }^{+} \mathrm{T}$ cells are the prominent cell type in chronic obstructive pulmonary disease (COPD). $\mathrm{CD} 8^{+} \mathrm{T}$ cells are increased in both the peripheral and central airways. Toll-like receptors (TLRs) are pathogen recognition receptors that regulate innate immunity and may play a protective role in chronic inflammatory diseases. It is thought that TLR ligands could be of potential therapeutic value for patients with COPD. We investigated the expression of TLR2, TLR4, TLR5, and TLR9 in bronchial biopsies of COPD patients with various severities. The main objective was to explore whether TLRs are expressed in $\mathrm{CD} 8^{+} \mathrm{T}$ cells.

METHODS: Single immunocytochemistry (ICC) was performed to detect TLR2, TLR4, TLR5 and TLR9 on endobronchial paraffin-embedded biopsies from COPD patients $(n=18)$. Double ICC was used to investigate the co-localization of the above TLRs and $\mathrm{CD} 8^{+} \mathrm{T}$ cells.

RESULTS: Immunoreactivity of the TLRs studied (2, 4, 5 and 9) were found in sections of all the biopsies. The highest expression was found for TLR4 and TLR9. Immunoreactivity of the receptors was demonstrated in the epithelium as well as in the subepithelial inflammatory cells. Double ICC staining using antibodies against TLRs and $\mathrm{CD} 8^{+} \mathrm{T}$ cells demonstrated that $40 \%-60 \%$ of the TLR4 and TLR9 positive cells were found to be $\mathrm{CD} 8^{+}$cells. Interestingly, $90 \%$ of the $\mathrm{CD}^{+} \mathrm{T}$ cells were TLR4 and TLR9 positive.
CONCLUSIONS: This is the first study that demonstrates the expression of TLR4 and TLR9 in CD8 ${ }^{+} \mathrm{T}$ cells in COPD patients. Our results suggest the possibility that the ligands of these receptors may modulate $\mathrm{CD} 8^{+} \mathrm{T}$ cell function in COPD patients.

\section{8}

\section{IMPLICATION DES RÉCEPTEURS PURINERGIQUES P2X DANS LA RÉPONSE VENTILATOIRE À L'HYPOXIE CHEZ DES RATS EN DÉVELOPPEMENT}

LM Niane ${ }^{1}$, DF Donnelly ${ }^{2}$, V Joseph ${ }^{1}$, A Bairam ${ }^{1}$

${ }^{1}$ Département de Pédiatrie, Centre de recherche de l'Hôpital St-François d'Assise, CHUQ, Université Laval, Québec, QC; Department of Pediatrics, Yale University School of Medicine, New Haven, CT, USA

INTRODUCTION: l'Adénosine Tri-Phosphate (ATP) est l'un des principaux neurotransmetteurs impliqués dans la réponse ventilatoire à l'hypoxie chez l'animal adulte tant au niveau des chémorécepteurs périphériques (corps carotidiens) qu’au niveau central (tronc cérébral). Il est admis que la stimulation de la ventilation par l'ATP est principalement due à l'activation des récepteurs purinergiques P2X2 et P2X3. Il reste néanmoins à déterminer si le système purinergique est impliqué dans l'expression de la réponse ventilatoire à l'hypoxie au cours du développement et si son rôle est influencé par lâge. Notons que l'expression de ces deux sous-types de récepteurs purinergiques n'a pas été démontrée âge dépendant dans le corps carotidien des chats en développement.

METHODE: La suramine (40 mg/kg, i.p.), un antagoniste des récepteurs P2X2 et P2X3, est utilisée afin de déterminer d'abord le rôle du système purinergique sur la ventilation (mesure in vivo par pléthysmographie). La fréquence respiratoire, le volume courant et la ventilation minute ont été enregistrés en condition de base (normoxie; $\mathrm{FiO}_{2}=21 \%$ ) et en réponse à une hypoxie modérée ( $\mathrm{FiO}=10 \%, 20$ minutes). Des rats répartis en deux groupes pour chacun des âges suivants: 1, 4, 7, 12, et 21 jours de vie ont été étudiés. L'un a reçu de la suramine $(40 \mathrm{mg} / \mathrm{kg}$, i.p.) et l'autre le salin (contrôle, i.p.). À la lumière des résultats obtenus, nous avons sélectionné trois âges afin d'identifier l'effet de la suramine $(100 \mu \mathrm{M})$ sur l'activité chémoréceptrice en ayant recours à l'enregistrement in vitro de fibres chémosensorielles du nerf du sinus carotidien. Deux conditions ont été étudiées : la solution de perfusion était saturée soit avec $21 \%$ d' $\mathrm{O}_{2}$ (normoxie) ou $5 \%$ d' $\mathrm{O}_{2}$ (hypoxie).

RESULTATS: In vivo, la réponse à l'hypoxie de chacun des paramètres ventilatoires est exprimée en \% de changement (hypoxie vs normoxie). En comparaison avec le groupe contrôle, la suramine a induit une diminution de la fréquence respiratoire à l'état stable (âge*traitement, $\mathrm{p}=0.002$ ). Elle a également réduit la ventilation minute pour chacun des âges étudiés (effet traitement, $\mathrm{p}=0.03$ ). Par contre, l'interaction âge*traitement n'est pas significative. Aucune variation du volume courant n'a été observée. In vitro, la suramine a réduit significativement l'activité chémoréceptrice en réponse à l'hypoxie, mais cet effet n'a pas été âge dépendant ( $\mathrm{p}=0.5)$.

CONCLUSION: L'ATP participe à l'expression de la réponse ventilatoire à l'hypoxie chez le nouveau-né comme c'est le cas chez l'adulte. L'absence d'une relation avec l'âge, quant à la mesure de l'activité des chémorécepteurs périphériques, suggère que le rôle du système purinergique au niveau central sur la respiration se modifie avec l'âge.

REMERCIEMENTS: PFRSRQ, Sick kids Foundation, Fondation des étoiles, IRSC

\section{9}

\section{EFFICACITÉ ET SÉCURITÉ DE LA VENTILATION LIQUIDIENNE TOTALE DANS UN MODÈLE EXPÉRIMENTAL NÉONATAL OVIN DE SYNDROME D'ASPIRATION MÉCONIALE}

O Avoine ${ }^{1}$, D Bossé ${ }^{1}$, B Beaudry², A Beaulieu², R Albadine ${ }^{3}$, R Robert ${ }^{2}$, JP Praud3, P Micheau ${ }^{2}$ and $H$. Waltit ${ }^{1}$

${ }^{1}$ Département de pédiatrie; ${ }^{2}$ Département de génie mécanique; ${ }^{3}$ Département de Médecine; Université de Sherbrooke, Sherbrooke, QC

Le SAM est une détresse respiratoire causé par l'inhalation périnatale de liquide amniotique méconiale. Sa forme sévère nécessite un support respiratoire invasif et mène à une importante morbidité et mortalité. Nous 
avons comparé un lavage bronchoalvéolaire en ventilation liquidienne totale (VLT-LBA) avec un LBA réalisé avec une solution de surfactant dilué (S-LBA).

20 agneaux nouveau-nés mâles (2.5-4 kg) ont été intubés, anesthésiés, curarisés et placés en ventilation gazeuse $\left(\mathrm{FiO}_{2}=1\right)$ avant la mise en place de cathéters pour la surveillance des GDS et de l'hémodynamique par thermodilution. $2 \mathrm{~mL} / \mathrm{kg}$ de méconium humain à $25 \%$ était administrés pour obtenir un SAM sévère avant randomisation. Le groupe VLT-LBA $(\mathrm{n}=10)$ était ventilé avec Inolivent-4 en utilisant du PFDEC (F2ChemicalsTM) à $160 \mathrm{ml} / \mathrm{kg} / \mathrm{min}$. Le groupe S-LBA $(\mathrm{n}=10)$ recevait deux LBA de $15 \mathrm{ml} / \mathrm{kg}$ à $5 \mathrm{mg} / \mathrm{ml}$ de surfactant (BLESTM) en ventilation gazeuse. Les GDS artériels, les paramètres hémodynamiques et ventilatoires ont été mesurés pour une durée totale de $4 \mathrm{~h}$ de ventilation optimisée avant l'euthanasie et le prélèvement du poumon droit.

Les résultats montrent que la VLT permet une $\mathrm{PaO} 2$ significativement supérieure au S-LBA $(219 \pm 59$ vs $74 \pm 34 \mathrm{mmHg})$ et ce dès la 5 e min. Aucune différence significative en ce qui concerne la $\mathrm{PaCO}_{2}$, le $\mathrm{pH}$ et les paramètres hémodynamiques sauf pour une augmentation de la PAP en VLT. La VLT permet de récupérer significativement plus de méconium vs le S-LBA ( $43 \pm 14$ vs $28 \pm 10 \%$ ). L'analyse histologique est en cours.

Dans ce modèle expérimental le VLT-LBA est plus efficace et plus sécuritaire que le S-LBA. La PAP en VLT demande à être adressée. Cette étude ouvre la voie à des études cliniques.

\section{0}

\section{VALIDATION DE 2 RÈGLES DE PRÉDICTION CLINIQUE POUR LE DIAGNOSTIC D'APNÉE OBSTRUCTIVE DU SOMMEIL}

\section{J Lemay, A-A Dussault, F Sériès}

Centre de recherche, IUCPQ, Québec, QC

INTRODUCTION: Le syndrome d'apnée obstructive du sommeil (SAOS) est un problème fréquent et actuellement la polysomnographie est considérée l'examen de choix pour en faire le diagnostic. Plusieurs stratégies ont été développées pour identifier les sujets à risque d'avoir un SAOS. BUT: Évaluer la valeur prédictive de 2 de ces règles et de l'oxymétrie nocturne chez 61 patients consécutifs référés à notre clinique du sommeil pour suspicion de SAOS, dont 9 patients en évaluation pré-opératoire de chirurgie bariatrique.

MÉTHODE: Le score clinique d'apnée du sommeil (SCAS) (Flemons et al., Am J Respir Crit Care Med 1994), le risque de SOAS identifié selon des caractéristiques anatomiques (Tsai et al., Am J Respir Crit Care Med 2003) et l'oxymétrie nocturne à domicile ont été obtenus avant de procéder à une polysomnographie standard.

RÉSULTATS: La prévalence de SAOS modéré, défini par un index d'apnées et d'hypopnées supérieur à $15 / \mathrm{h}$, a été de $72 \%$. Un SCAS supérieur à 15 était associé à une augmentation de 17 fois du risque de SAOS. Ajouter les résultats de l'oxymétrie nocturne n'améliorait pas ce score. Lorsque la somnolence diurne (score d'Epworth supérieur à 10) est incluse dans la définition de SAOS, le SCAS n'est plus utile pour prédire le risque. La méthode rapportée par Tsai n'a pas permis de prédire la présence ou l'absence de SAOS. L'oxymétrie nocturne seule, en utilisant une valeur seuil d'index anormal de désaturation de $15 / \mathrm{hr}$, avait une sensibilité de $30 \%$ et spécificité de $100 \%$.

CONCLUSION: Les règles de prédiction clinique diffèrent dans leur capacité de diagnostiquer un SAOS. Leur utilité est hautement variable d'un centre à l'autre.

Supporté par CIHR grant MT13768

\section{1}

\section{L'AUTO-ÉVALUATION DE LA MAÎTRISE DE L'ASTHME AVANT ET APRÈS L'ÉDUCATION DU PATIENT - L'EXPÉRIENCE DU CHUM}

Julie Morisset, Amal Robay, Yvon Dubois InhT, Elise O'Carroll, Céline Bergeron

Service de Pneumologie, CHUM Hôtel-Dieu de Montréal, Montréal, QC

Plusieurs études ont démontré les effets bénéfiques de l'éducation sur l'asthme chez les adultes. Une enquête préliminaire avait démontré une amélioration de la maîtrise de l'asthme suivant l'éducation aux patients au CHUM. Toutefois nous avons aussi voulu déterminer l'efficacité de l'enseignement dans notre milieu en observant l'aptitude des patients éduqués à évaluer la maîtrise de l'asthme à long terme. À l'aide d'un questionnaire téléphonique, nous avons réalisé une enquête chez les sujets ayant eu un enseignement entre octobre 2006 et juillet 2008. Les paramètres étudiés étaient la maîtrise de l'asthme selon le patient, la maîtrise de l'asthme selon les critères de maîtrise en accord avec les recommandations canadiennes, les exacerbations, l'utilisation du plan d'action, la prise de prednisone, les visites non prévues, les visites à l'urgence et les hospitalisations, et ce pour l'année précédent et suivant à l'enseignement. Nous avons rejoint 122 patients. Parmi les sujets sondés, 87,7\% considéraient leur asthme bien maîtrisé et la bonne maîtrise de l'asthme selon les critères objectifs était de $77 \%$. Le nombre d'exacerbations a significativement diminué dans l'année suivant l'enseignement ainsi que le nombre de consultations à l'urgence. De façon inattendue, nous avons démontré que la majorité des patients (77\%) étaient capables d'évaluer avec justesse le niveau de maîtrise de leur asthme, et ce en corrélant les résultats avec les différents critères de mâ̂trise de l'asthme. L'éducation sur l'asthme, en plus de contribuer à la meilleure maitrise de l'asthme, permet également une meilleure connaissance de la maladie et ses critères de maitrise.

\section{2}

EST-CE QUE LE POTENTIEL DE RÉGÉNÉRATION EST ALTÉRÉ DANS LES MUSCLES SQUELETTIQUES DE PATIENTS AYANT UNE MALADIE PULMONAIRE OBSTRUCTIVE CHRONIQUE (MPOC)?

M-E Thériault, M-A Caron, B Lemire, M-E Paré, F Maltais, R Debigaré

Centre de recherche de I'Institut universitaire de cardiologie et de pneumologie de Québec, QC

La maladie pulmonaire obstructive chronique est caractérisée par une obstruction bronchique conduisant fréquemment à une atrophie musculaire périphérique. Un déficit dans la régénération du tissu musculaire, qui est du ressort des cellules satellites, pourrait contribuer au développement de l'atrophie musculaire. Un nombre insuffisant de cellules satellites combiné ou non à un processus de multiplication et de différenciation déficient pourrait altérer la capacité du tissu musculaire à récupérer adéquatement suite à un dommage musculaire. Nous proposons l'hypothèse que le potentiel de régénération est altéré chez les patients ayant une MPOC. Nous avons développé un modèle de culture primaire des cellules satellites musculaires provenant de biopsies du vastus lateralis de sujets ayant ou non une MPOC. Le phénotype des cellules en cultures a été vérifié par l'expression des marqueurs spécifiques Pax7 et la chaîne lourde de myosine au stade de myoblaste et myotube respectivement. Les cellules satellites mises en cultures provenant de patients ayant une MPOC ont nécessité un délai supplémentaire de $7.25 \pm 0.25$ jours pour apparaître en culture comparativement à 5.50 \pm 0.29 jours avec les cultures contrôles $(\mathrm{p}<0.05)$. La différenciation semble être altérée dans les cultures primaires provenant de sujet ayant une MPOC comparativement à celles des sujets contrôles tel qu'observé par la diminution de l'expression de la chaîne lourde de myosine de $44.9 \%$, 43.5\% et $48.1 \%$ aux jours 5,6 et 7 respectivement $(\mathrm{p}<0.1)$. Ce projet permettra de déterminer l'implication des cellules satellites dans le développement de l'atrophie musculaire observée chez des patients ayant une MPOC.

\section{3}

\section{VALIDATION D'UN MODÈLE OVIN NOUVEAU-NÉ POUR L'ÉTUDE DE LA DÉGLUTITION NUTRITIVE ET DE SA COORDINATION AVEC LA RESPIRATION.}

A Bernier, $S$ Brisebois, N Samson, J-P Praud.

Département de pédiatrie, Université de Sherbrooke, Sherbrooke, QC INTRODUCTION : Les problèmes de déglutition nutritive (DN) et de coordination $\mathrm{DN}$-respiration sont très fréquents en néonatologie. Si plusieurs études chez le nouveau-né humain ont été réalisées (Barlow S, 2009), un seul modèle animal néonatal a été publié (German RZ, 1996). L'OBJECTIF de cette étude pilote est de valider la pertinence de l'agneau nouveau-né pour étudier la DN et la coordination DN-respiration. 
MÉTHODES : Les agneaux ont été instrumentés chirurgicalement afin d'enregistrer les DN, la respiration, l'ECG et la SatO2 durant la prise d'un biberon. La possibilité d'utiliser 2 analyses décrites pour le nouveau-né humain a été testée: fréquence des DN et des respirations, moment de survenue de la $\mathrm{DN}$ dans le cycle respiratoire (inspiration, expiration, ou transition entre les 2) (Reix P, 2003) et temps entre une DN et la respiration suivante (Gewolb I, 2006).

RÉSULTATS : Les analyses ont été validées chez un modèle ovin néonatal de laryngite de reflux modérée (instillation de pepsine $+\mathrm{HCl}$ à $\mathrm{pH} 2$ durant 6 jours, $n=4$ ) vs un groupe contrôle (instillation de salin, $n=6$ ). Le calcul des paramètres a aisément été réalisé et a montré une diminution de la fréquence des $\mathrm{DN}(\mathrm{DN} / \mathrm{min})(\mathrm{p}=0,055)$ sans altération de la coordination $\mathrm{DN}$-respiration chez le groupe laryngite.

CONCLUSIONS : 1) Une laryngite de reflux modérée a peu d'impact sur la DN et la coordination DN-respiration 2) l'agneau nouveau-né semble être un modèle pertinent d'étude des problèmes DN-respiration; les études à venir sur ce modèle devront s'intéresser à l'impact d'une CPAP nasale, de la prématurité et/ou d'une infection par le virus respiratoire syncytial. SUPPORT : IRSC; Université de Sherbrooke

\section{4}

\section{EFFET DE L'HYPERVENTILATION EUCAPNIQUE SUR LA RÉPONSE À LA MÉTACHOLINE CHEZ L'ATHLÈTE}

\section{E Blouin, V Bougault, J Turmel, L-P Boulet}

Centre de recherche de I'Institut universitaire de cardiologie et de pneumologie de Québec, Québec, QC

INTRODUCTION : L'hyperventilation eucapnique (HVE) et la provocation à la métacholine (PM) sont couramment utilisées pour évaluer la réactivité bronchique des athlètes. L'HVE et la PM sont souvent effectuées consécutivement. Il est cependant possible que l'HVE influence la réactivité bronchique au test à la métacholine (période réfractaire).

OBJECTIF : Évaluer les effets de l'HVE sur la réponse à la métacholine chez l'athlète avec ou sans hyperréactivité bronchique (HRB) ainsi que chez le sujet témoin.

METHODES : Deux PM (une PM seule et une précédée de l'HVE) ont été effectuées de façon aléatoire chez 10 athlètes avec HRB $(\mathrm{CP} 20<16 \mathrm{mg} / \mathrm{mL})$, 16 athlètes sans $\mathrm{HRB}(\mathrm{CP} 20>16 \mathrm{mg} / \mathrm{mL})$ et 11 sujets témoins.

RESULTATS : Chez les athlètes avec HRB, la CP20 (exprimée par la moyenne de doubles concentrations (DC) \pm écart-type) était inférieure de $0,7 \pm 1,2 \mathrm{DC}(\mathrm{p}=0,015)$ lorsque la PM suivait l'HVE, alors qu'aucune différence significative n'était observée chez les athlètes sans $\operatorname{HRB}(-0,4 \pm 0,8$ $\mathrm{DC})$ et chez les sujets témoins $(0,4 \pm 0,7 \mathrm{DC})$. En regroupant tous les sujets ayant une réponse positive à l'HVE (chute du VEMS $\geq 10 \%$ ), on constate que ces derniers ont une CP20 inférieure de 0,8 $\pm 1,1 \mathrm{DC}(\mathrm{p}=0,0008)$ lorsque la PM suit l'HVE. La CP20 des sujets négatif à l'HVE (chute du VEMS $<10 \%)$ n'est cependant pas influencée par ce test $(0,05 \pm 0,76 \mathrm{DC})$. CONCLUSION : L'HVE augmente légèrement la réponse à la PM subséquente chez les athlètes avec HRB alors qu'elle n'influence pas celle des athlètes sans HRB et des témoins. De plus, les sujets avec une réponse positive à l'HVE ont une CP20 diminuée à la PM subséquente. Ces 2 tests devraient donc être effectués lors de sessions différentes.

\section{5}

\section{ASSOCIATION ENTRE L'APNÉE-HYPOPNÉE DU SOMMEIL} (AHS) ET L'HYPERTENSION GESTATIONNELLE ANTÉRIEURE (HG)

I Boutin, K Champagne, K Schwartzman, SL Tan, L Lavigne,

RJ Kimoff

Division de Pneumologie et Department d'Obstétrique,

Centre Universitaire de Santé McGill; Université McGill, Montréal, QC CONTEXTE: L'AHS est un facteur indépendant dans le développement de l'hypertension dans la population générale. Nous avons récemment démontré une association importante entre l'HG et l'AHS chez la femme enceinte pendant la grossesse. Il est aussi reconnu que les femmes ayant présenté une HG sont plus à risque de comorbidités cardio-vasculaires plus tard dans la vie, notamment l'hypertension chronique. Notre hypothèse est qu'elles sont également plus susceptibles de souffrir d'AHS.
OBJECTIF: Déterminer la prévalence actuelle de l'AHS chez les femmes avec ou sans antécédent d'HG.

MÉTHODES: Dans cette étude transversale cas-témoin, des femmes ayant donné naissance entre 1989 et 1998 suite à une grossesse unique avec ou sans HG ont été sélectionnées aléatoirement. Une entrevue, un examen physique, une mesure ambulatoire de la pression artérielle (MAPA) et une polysomnographie complète ont été réalisés. AHS est défini par un index d'apnée-hypopnée (IAH) >15/h.

RÉSULTATS: Une analyse intérimaire a été réalisée chez 15 femmes avec antécédent d'HG et 15 témoins. L'hypertension chronique est présente chez $47 \%$ des sujets avec HG vs. $7 \%$ des témoins ( $\mathrm{p}=0.016$ ). Parmi les femmes HG, $73 \%(11 / 15)$ présentent un AHS, contre seulement $20 \%$ (3/15) des témoins $(\mathrm{p}=0.004)$. L'IAH moyen est de $19.7 \pm 9.7$ dans le groupe $\mathrm{HG}$ vs $11.2 \pm 7.0$ ( $\mathrm{p}=0.011)$. Après ajustement pour l'âge et l'IMC par régression logistique, le rapport de cote pour l'interaction entre l'AHS et l'HG est de 10.6 (1.7 - 96.3 IC 95\%).

CONCLUSIONS : L'HG antérieure est fortement associée à l'AHS, indépendamment de l'IMC.

Subventionné par le Réseau de Santé Respiratoire du FRSQ et l'Institut de Recherche CUSM.

\section{6}

\section{INHALED CORTICOSTEROIDS ACCELERATE AIRWAY SMOOTH MUSCLE REMODELING REVERSIBILITY IN AN EQUINE MODEL OF CHRONIC ASTHMA}

M Leclère ${ }^{1}$, A Lavoie-Lamoureux ${ }^{1}$, J G Martin², JP Lavoie ${ }^{1}$

${ }^{1}$ Université de Montréal; ${ }^{2}$ Meakins-Christie Laboratories, McGill University, Montreal, QC

RATIONALE: Heaves is a naturally occurring disease of horses that shares similarities with chronic asthma. Affected horses have more than twice as much airway smooth muscle (ASM) as controls, and this remains unaltered by short periods of antigen exposure or avoidance. The objective of this study was to evaluate the effect of prolonged corticosteroid administration and antigen avoidance on ASM remodeling reversibility.

METHODS: Eleven adult horses with heaves were exposed to environmental antigens and developed airway obstruction ("baseline"). Five horses were then maintained in a low-antigen environment without additional treatment for 12 months ("antigen avoidance"). The remaining 6 horses were treated with fluticasone (with antigen exposure for 6 months, then combined with antigen avoidance). Lung function and ASM were measured at baseline, and after 6 and 12 months. Additionally, ASM was measured in 5 age-matched controls.

RESULTS: Lung resistance of horses with heaves decreased in the first 6 months $(p<0.001)$ in both groups, and then stabilized. There was a moderate decrease in ASM at 6 months in fluticasone-treated horses $(p<0.05)$ and in both groups at 12 months (approximately 30\%, p<0.04). ASM mass remained higher in diseased horses than in their age-matched controls. CONCLUSIONS: ASM remodeling is partially reversible in horses with chronic heaves. Inhaled corticosteroids accelerated the decrease in ASM compared to antigen avoidance alone. However, a component of remodeling appears to be refractory to intervention, whether it is prolonged antigen avoidance or corticosteroids.

Supported by the Canadian Institutes of Health Research and AllerGen NCE.

\section{7}

ASSOCIATION ENTRE LE GÈNE FILAGGRINE ET L'ASTHME AVEC HISTOIRE DE DERMATITE ATOPIQUE DANS L'ÉCHANTILLON FAMILIALE ORIGINAIRE DU SAGUENAY-LAC-SAINT-JEAN

Marie-Hélène Lambert ${ }^{1,2}$, Karine Tremblay ${ }^{3}$, Anne-Marie Madore ${ }^{1,2}$, Catherine Laprise $^{1}$

${ }^{1}$ Université du Québec à Chicoutimi; ${ }^{2}$ Université Laval, Québec;

${ }^{3}$ Université de Montréal, Montreal, QC

CONTEXTE: Le gène filaggrine (FLG) code pour une protéine qui se retrouve dans les kératinocytes et qui a pour rôle l'arrangement des filaments de kératines dans l'épiderme et donc un rôle important pour la barrière épithéliale (1). Plusieurs études ont démontré qu'une défectuosité au 
niveau de ce gène pouvait être un facteur déterminant pour plusieurs maladies atopiques comme la dermatite atopique et l'asthme (2).

OBJECTIFS: Démontrer une association entre la filaggrine et l'asthme et la dermatite atopique.

MÉTHODE: Un Genome-wide association study (GWAS) a été réalisé pour la collection familiale d'asthme originaire du Saguenay-Lac-St-Jean. Les polymorphismes (SNP) se retrouvant dans le gène FLG incluant ceux dans les régions 3' et 5' UTR ont été extraits. Une étude d'association entre l'asthme, la dermatite atopique et les SNP de FLG a été faite à l'aide du Family-based association test (FBAT). Les résultats ont été corrigés par la méthode de Li et Ji (3).

RÉSULTATS: Le polymorphisme rs3126085 de FLG est associé à l'asthme dans l'échantillon familial du Saguenay-Lac-St-Jean $(\mathrm{p}=0,0010)$. De plus, les SNP rs2065954 et rs3818831 du gène FLG ont été associés avec la dermatite atopique (respectivement, $\mathrm{p}=0,0015$ et $\mathrm{p}=0,0006$ ).

PERSPECTIVES: L'étude fonctionnelle permettra de définir le rôle de ce gène dans la pathophysiologie de ces affections.

1. J Cell Sci 2009 May 1;122(Pt 9):1285-94.

2. J Allergy Clin Immunol. 2009 Jun;123(6):1361-70.e7.

3. Heredity 2005 Sep;95(3):221-7.

\section{8}

ENHANCED CALCIUM ENTRY IN CELLS EXPRESSING DELF508 CFTR: CROSSTALK BETWEEN THE ER-RESIDENT PROTEIN STIM1, CFTR AND ORAI1

H Balghi ${ }^{1}$, R Robert ${ }^{1}$, A Evagelidis ${ }^{1}$, Luo $^{1}$, J Goepp ${ }^{1}$, DY Thomas ${ }^{3}$, JW Hanrahan ${ }^{1,2}$

Departments of ${ }^{1}$ Physiology, ${ }^{2}$ McGill University Health Centre

Research Institute, ${ }^{3}$ Biochemistry, McGill University, Montréal, QC

BACKGROUND: The endoplasmic reticulum (ER) is a major site of intracellular calcium $\left(\mathrm{Ca}^{2+}\right)$ storage, and altered $\mathrm{Ca}_{2}{ }^{+}$signalling in $\mathrm{CF}$ airway epithelial cells have been shown although the mechanisms remain unclear (Ribeiro et al., 2005). We investigated the role of CFTR in $\mathrm{Ca}^{2+}$ homeostasis during $\mathrm{Ca}^{2+}$ store depletion. Depleting $\mathrm{Ca}^{2+}$ stores causes the ER-resident $\mathrm{Ca}^{2+}$ sensor protein STIM1 (stromal interaction protein 1) to associate with the plasma membrane (PM), where it interacts and forms punctuate with $\mathrm{Ca}^{2+}$ release-activated $\mathrm{Ca}^{2+}$ channel (CRAC) protein called Orai and/or TRPC channels which in turn activate $\mathrm{Ca}^{2+}$ influx.

METHODS: CFBE cells expressing WT or delF508 CFTR were loaded with the $\mathrm{Ca}^{2+}$ probe Fura-2 and we monitored the rate of quench induced by $\mathrm{Mn}^{2+}$ influx after CPA-induced $\mathrm{Ca}^{2+}$ stores depletion. TIRF and confocal imaging were used to localize CFTR, STIM1 and Orail proteins.

RESULTS: The rate of quench by $\mathrm{Mn}^{2+}$ was two-fold greater in delF508 CFTR cells than in WT. $\mathrm{Ca}^{2+}$ influx was abolished by 2 -APB, an inhibitor of capacitative $\mathrm{Ca}^{2+}$ entry. Expression of Orai1 and STIM1 was demonstrated by Western blotting however no difference in the localization of these proteins was detected by confocal microscopy. The movement of the ER and STIM1-GFP, and the interaction with the PM during store depletion were studied by TIRF imaging. Aggregates form of STIM1 and Orai1 at the PM during CPA-mediated $\mathrm{Ca}^{2+}$ store depletion occurred in both WT and delF508 cells indicating that delF508- CFTR retention in the ER does not alter ER movement or STIM1 migration to the PM. Co-immunoprecipitation studies showed that both delF508- CFTR and WT-CFTR interact with STIM1.

CONCLUSION: These results suggest that, (i) the activity of CRAC channels is increased when CFTR trafficking to the PM is defective, and (ii) CFTR might influence formation of STIM1/Orai1 aggregates at the PM during $\mathrm{Ca}^{2+}$ store depletion. Supported by a CCFF fellowship and grants from CIHR, CCFF and CFFT.

\section{9 \\ MÉCANISMES DE RÉGULATION DE ENAC PAR LES CANAUX POTASSIQUES}

O Bardou, A Privé, NTN Trinh, A Dagenais, Y Berthiaume,

E Brochiero

Département de Médecine, Université de Montréal, Montréal, QC

L'épithélium pulmonaire est responsable du transport des ions et fluides, permettant de maintenir un environnement exempt de liquide, pour un échange gazeux efficace. Diverses pathologies comme l'ARDS entrainent un œè̀me pulmonaire sévère dont la résolution est dépendante de l'absorption ionique et liquidienne par les cellules alvéolaires. Il est donc primordial de maintenir, voir de promouvoir, ces transports pour le bon fonctionnement du poumon et la résolution de ces pathologies.

Nous avons préalablement montré que la modulation de l'activité des canaux $\mathrm{K}^{+} \mathrm{KATP}$ et KvLQT1, régulait non seulement l'activité mais aussi l'expression du canal $\mathrm{ENaC}$, ainsi que l'absorption liquidienne au travers de l'épithélium alvéolaire. Nous avons voulu étudier plus finement les mécanismes de régulation du canal $\mathrm{ENaC}$ par les canaux $\mathrm{K}^{+}$. Afin de prouver le rôle de ces canaux, nous avons démontré que des siRNA dirigés contre KvLQT1 diminuaient de 30\% l'expression génique d'ENaC. De plus l'activation des canaux $\mathrm{K}^{+}$KATP et KvLQT1 permet une augmentation (jusqu'à 60\%) de l'activité du promoteur de $\alpha \mathrm{ENaC}$ tandis qu'en inhibant ces canaux (avec glibenclamide et clofilium), on obtient une diminution significative de l'activité du promoteur de $\alpha \mathrm{ENaC}$. Nos résultats préliminaires indiquent que les voies de signalisation $\mathrm{Ca}^{2+}$, ERK et p38 semblent impliquées. En effet en chélatant les ions Ca2+ (BAPTA) ou en inhibant les voies p38 (SB203580) ou ERK (PD98059), l'effet des inhibiteurs des canaux $\mathrm{K}^{+}$est partiellement reversé.

Ces résultats vont nous aider à mieux comprendre les mécanismes de régulation du canal $\mathrm{ENaC}$, primordial au contrôle des fluides alvéolaires.

\section{0}

LES NIVEAUX D'EXPRESSION PULMONAIRE ET

PLACENTAIRE DE LA $17 \beta$-HYDROXYSTÉROÏDE DÉSHYDROGÉNASE DE TYPE 2 SONT-ILS EN RELATION AVEC LES NIVEAUX D'ESTRADIOL ET DE PROGESTÉRONE MATERNELS ET FOETAUX

\section{G Cormier, P Provost, Y Tremblay}

Axe reproduction, santé périnatale et santé de l'enfant, Centre de Recherche en Biologie de la Reproduction (CRBR), Centre de recherche du CHUL, Université Laval, Québec, QC

Introduction : L'estradiol accélère la maturation pulmonaire alors que les androgènes exercent l'effet opposé. La 17ß-hydroxystéroïde déshydrogénase (HSD)-2 est capable d'inactiver androgènes et estrogènes et présente une modulation de son expression lors du développement pulmonaire. Chez la souris gestante, les niveaux plasmatiques d'estradiol et de progestérone atteignent un maximum au jour de gestation (JG) 17.5, moment qui coïncide avec un pic d'expression du gène $17 \beta-H S D-2$ dans le poumon foetal. De plus, une grande variation inter-portée est observée dans son expression à ce même JG. Objectif : Établir s'il existe une relation entre les niveaux d'estradiol foetaux et les niveaux d'expression du gène 17 $\beta$-HSD-2 dans le poumon au JG 17.5. Une comparaison est également effectuée entre les concentrations circulantes d'estradiol et de progestérone maternelles, les niveaux d'expression de la 17 $\beta$-HSD-2 placentaire et les concentrations d'estradiol et de progestérone foetales dans le modèle murin Balb/c. Méthodologie : Les niveaux d'estradiol et de progestérone sont mesurés par GC/MS et l'expression du gène $17 \beta-H S D-2$ pulmonaire et placentaire est déterminée par PCR quantitatif. Résultats : Les niveaux d'estradiol foetaux (entre 11.65 et $52.66 \mathrm{pg} / \mathrm{g}$ ) corrèlent significativement avec les niveaux d'estradiol maternels (entre 5.36 et $43.13 \mathrm{pg} / \mathrm{mL}$ ) alors que ce n'est pas le cas pour les niveaux de progestérone. Les niveaux d'estradiol maternels et foetaux ne corrèlent pas avec la 17 $\beta$-HSD-2 placentaire. Il ne semble pas y avoir de lien entre les niveaux d'estradiol foetaux et la 17ß-HSD-2 pulmonaire. Ces résultats laissent sous-entendre qu'une régulation fine des stéroïdes pourrait avoir lieu dans le poumon foetal. 
31

ÉTUDE COMPARATIVE DU PROFIL D'EXPRESSION GÉNOMIQUE DES MACROPHAGES ALVÉOLAIRES DANS L'ASTHME CHEZ L'HUMAIN ET CHEZ LE RAT

A-M Madore ${ }^{1,2}$, V Turmel $^{3}$, A Dubé ${ }^{3}$ M Laviolette ${ }^{1,3}$, C $_{\text {Laprise }}^{2}$, EY Bissonnette ${ }^{1,3}$

${ }^{1}$ Université Laval; ${ }^{2}$ Université du Québec à Chicoutimi;

${ }^{3}$ Unité de recherche en pneumologie, Hôpital Laval, Québec, QC

CONTEXTE : La caractérisation des modèles animaux utilisés en recherche est essentielle. Dans la recherche sur l'asthme, un des modèles fréquemment utilisés est le rat Brown Norway (BN). La comparaison entre le profil d'expression génomique des macrophages alvéolaires (MA) de sujets asthmatiques allergiques avec celui des MA de rats BN sensibilisés devrait permettre de mieux caractériser ce modèle animal dans l'asthme. OBJECTIFS : Établir le profil d'expression génomique des MA de rats BN sensibilisés à l'ovalbumine en comparaison aux rats témoins. Comparer la liste des gènes différemment exprimés obtenue avec celle résultant de l'étude antérieure réalisée chez l'humain.

MÉTHODE : Des rats mâles $\mathrm{BN}$ ont été traités par injections intrapéritonéales d'ovalbumine ou de saline. Après purification des MA à partir d'un lavage bronchoalvéolaire, l'ARN a été extrait puis hybridé sur les puces RatGene1.0ST d'Affymetrix. L'analyse des données a été réalisée à l'aide du logiciel Bioconductor.

RÉSULTATS : Dans les 2 études, une proportion similaire de gènes différemment exprimés est classée dans les catégories fonctionnelles reliées à la réponse immunitaire ( $38 \%$ chez l'humain et $43,5 \%$ chez le rat). De plus, plusieurs gènes de la famille des heat shock proteins (HSP) se retrouvent dans les deux études. Les similarités observées entre les résultats des 2 études soulignent l'intérêt de ce modèle dans l'asthme, particulièrement au niveau du transcriptome, ainsi que l'importance des HSP dans les fonctions des MA dans l'asthme.

PERSPECTIVES : Une étude de profil d'expression génomique sera également réalisée en comparant le transcriptome de rats BN témoins et exposés à l'antigène.

\section{2}

TITRE : IMPACT DU STRESS OXYDATIF SUR LE TRANSCRIPTOME D'UNE LIGNÉE HUMAINE DE CELLULES ÉPITHÉLIALES BRONCHIQUES PORTEUSES DE LA MUTATION $\triangle$ F508

Grégory Voisin ${ }^{1}$, André Dagenais ${ }^{1}$, Sébastien Lemieux², Yves Berthiaume ${ }^{1}$

${ }^{1}$ CRCHUM, Hôtel-Dieu, Université de Montréal et ${ }^{2}$ IRIC, Université de Montréal, Montréal, QC

INTRODUCTION: Le stress oxydatif a d'importantes conséquences sur la physiopathologie de la fibrose kystique. Pour comprendre son implication sur le transcriptome d'une cellule CF (cystic fibrosis), nous avons comparé le niveau absolu de l'expression de 38000 transcripts de 2 lignées cellulaires épithéliales bronchiques humaines $(\Delta \mathrm{F} 508$ et non-CF) en présence et en absence de DMNQ, un inducteur du stress oxydatif

MÉTHODOLOGIE: Nous avons sélectionné les transcripts par une méthode non paramétrique de quantification de la variance appelée analyse de redondance. Celle-ci juge de l'influence des deux conditions expérimentales sur la variation de l'expression des transcripts. De cette façon, nous avons isolé les transcripts dont la variance est expliquée par au moins $20 \%$ de chacune des conditions. Ceux-ci ont été classés selon leurs profils d'expression définissant des classes de modulations. Finalement, une analyse ontologique, a mis en avant les fonctions biologiques significativement surreprésentées dans chaque classe.

RÉSULTATS: Notre analyse a mis en évidence la modulation de transcripts impliqués dans l'activité des MAP Kinases, de la régulation de l'apoptose et de la prolifération cellulaire.

CONCLUSION: Basé sur une analyse de la variance de données transcriptomiques, notre approche exploite plusieurs variables expérimentales tout en évitant les contraintes des tests statistiques multivariés usuels. L'interprétation de nos résultats suggère que la mutation et le stress oxydatif module des fonctions biologiques qui pourraient êtres impliquées dans la prolifération et la réparation cellulaire.

\section{3}

\section{SMALL AIRWAY EPITHELIAL-MESENCHYMAL TRANSITION INDUCED BY ENDOTHELIAL APOPTOSIS}

A Al Rabea, S Ptaszinski, A Robay, M-J Hebert, C Bergeron

CRCHUM Hotel-Dieu, Montréal, QC

BACKGROUND: Bronchiolitis obliterans is the leading cause of long term mortality in lung transplant recipients, and is characterized by small airway remodelling. Epithelial-mesenchymal transition (EMT) is a process by which epithelial cells undergo phenotypic transition to mesenchymal cells, and this process has been linked to fibrosis. Endothelial apoptosis not only leads to elimination of cells, but also triggers extracellular matrix (ECM) proteolysis and production of fibrogenic fragments of ECM. We propose that endothelial apoptosis through proteolysis of the surrounding ECM and release of cryptic fibrogenic factors stimulates EMT in small airway.

AIM: To study the effect of endothelial apoptosis on the induction of EMT in small airway epithelial cells (SAEC).

METHODS: Human SAEC were stimulated or not with $100 \%$ of conditioned medium derived from apoptotic human endothelial cells. SAEC were also stimulated with non apoptotic medium and TGF-b1. Immunofluorescence and real time-PCR for -smooth muscle actin (SMA) and collagen I were performed to detect EMT.

RESULTS: Increased immunoreactivities for collagen I (from 32 to $78 \%$ ) and -SMA (from 15\% to 30\%) were observed in SAEC stimulated, for 48 hours, with conditioned. This increased expression of both markers was of similar magnitude to TGF-bland of higher magnitude when compared to non apoptotic conditioned medium. Expressions of collagen I mRNA (3.6X) and SMA (3.2X) were increased in SAEC stimulated by conditioned medium for 24 hours when compared to RPMI.

CONCLUSION: Paracrine mediators produced by apoptotic endothelial cells induce features of EMT in SAEC. These findings may be relevant to bronchiolitis obliterans

\section{4}

\section{SMOOTH MUSCLE REGULATORY PROTEIN EFFECT ON THE BINDING FORCE OF UNPHOSPHORYLATED MYOSIN TO ACTIN}

Horia Nicolae Roman ${ }^{1}$, Nedjma B Zitouni ${ }^{1}$, Apolinary Sobieszek ${ }^{2}$, Anne-Marie Lauzon ${ }^{1}$

${ }^{1}$ Meakins-Christie Laboratories, McGill University, Montréal, QC;

${ }^{2}$ Institute for Biomedical Aging Research, Austrian Academy of

Sciences, Innsbruck, Austria

Smooth muscle (SM) is unique in its ability to maintain force for long periods of time at low energy cost, property called the latch-state. One of the assumptions of the latch state model of Hai and Murphy is that myosin must first be phosphorylated in order to attach to the thin filament. However, we previously demonstrated that unphosphorylated (unPHOS) myosin can attach to unregulated actin filaments. The goal of this study was to measure the binding force of unPHOS SM myosin to tropomyosinregulated actin filaments. A microsphere captured in a laser trap was attached to an actin filament decorated with SM tropomyosin. The filament was brought in contact with a pedestal coated with unPHOS myosin. The pedestal was then moved away from the trap at constant velocity. Despite pulling the pedestal, the microsphere did not move until the force exerted by the trap on the microsphere was sufficient to overcome the binding force of myosin on the actin/tropomyosin filament, when the microsphere sprang back to its unloaded position. The force of unbinding was calculated as the product of the trap stiffness and the maximal displacement of the trapped microsphere, as assessed by displacement of its center of mass. The average force of unbinding per myosin molecule (Funb) was obtained by dividing the measured force of unbinding by the number of myosin molecules estimated per actin filament length. Funb was greater in presence $(0.222 \mathrm{pN} \pm 0.018$; mean $\pm \mathrm{SD})$ than in absence $(0.142 \mathrm{pN} \pm 0.019 ; \mathrm{p}<0.001)$ of tropomyosin. These results demonstrate that tropomyosin strengthens the bond between unPHOS myosin and actin. Future studies will investigate the role of other SM regulatory proteins. 
35

EFFET DE L'IL-17 SUR LE RECRUTEMENT DES NEUTROPHILES À L'ENDOTHÉLIUM DANS LES MALADIES PULMONAIRES

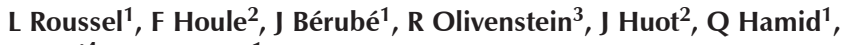
L Ferri' $^{4}$, S Rousseau ${ }^{1}$

${ }^{1}$ Meakins-Christie Laboratories; ${ }^{2}$ Le Centre de recherche en cancérologie de l'Université Laval, Québec, QC; ${ }^{4}$ Royal Victoria Hospital and ${ }^{3}$ Montreal Chest Institute, McGill University Health centre Research Institute, Montreal, QC

L'inflammation neutrophilique tient un rôle important dans la destruction tissulaire du poumon dans certaines maladies chroniques comme la fibrose kystique, l'emphysème ou l'asthme sévère. Le recrutement des neutrophiles aux sites inflammatoires se fait en partie via l'action de l'interleukine-17 (IL-17). Nous avons observé une augmentation significative de l'expression de l'ARN messager du récepteur A à l'IL-17 (IL-17RA) dans les bronchoscopies de patients asthmatiques. En plus de l'expression de IL-17RA dans les cellules épithéliales et les cellules inflammatoires, nous avons identifié une localisation endothéliale. L'IL-17 peut stimuler les cellules endothéliales microvasculaires de poumons pour produire des chemoattractants neutrophiliques tel que l'interleukine-8. De plus, l'IL- 17 est capable d'activer l'endothélium en stimulant l'expression des molécules d'adhésion (Selectine-E, VCAM-1 ; ICAM-1) et ce dépendant de la voie p38 MAPkinase. Cette augmentation explique l'effet de l'IL-17 sur la stimulation de la trans-migration et de l'adhésion endothéliale des neutrophiles in vitro et in vivo respectivement. Nos résultats démontrent donc que l'IL-17 est un puissant activateur de l'endothélium permettant le recrutement des neutrophiles sur les sites d'inflammation locale. Par conséquent, la diminution du recrutement neutrophilique à travers l'action de l'IL-17 dans les cellules endothéliales peut être véritablement bénéfique dans un grand nombre de maladies inflammatoires avec neutrophilie.

\section{6}

\section{CONTRÔLE DE LA RÉPONSE IMMUNOPATHOLOGIQUE AU VIRUS DE L'INFLUENZA PAR L'ACTIVATION DES RÉCEPTEURS DE LA SPHINGOSINE-1-PHOSPHATE}

\section{David Marsolais}

Centre de recherche de l'institut universitaire de cardiologie et de pneumologie de Québec; Faculté de médecine, Université Laval, Québec, QC

La pathogénicité des virus de l'influenza résulte de l'activité cytolytique intrinsèque de ces virus et de l'intensité de la réponse immune qu'ils déclenchent. En effet, une réponse immune agressive cause des dommages aux tissus sains, donc le contrôle de cette réaction immunopathologique est susceptible d'améliorer le pronostique de guérison. La sphingosine-1-phosphate $(\mathrm{S} 1 \mathrm{P})$ et ses récepteurs (S1P1 à S1P5) émergent en tant que régulateurs primordiaux de la réponse immune, mais leur potentiel thérapeutique n'a jamais été testé suivant une infection virale. Le but de nos travaux était donc de déterminer l'effet de l'administration pulmonaire d'un activateur des récepteurs de la S1P sur la réponse immunopathologique induite par le virus de l'influenza chez la souris. Nos résultats démontrent que l'administration locale d'une seule dose d'un agoniste des récepteurs de la S1P inhibe la libération de cytokines pro-inflammatoires ainsi que l'activation des cellules dendritiques au jour 2 suivant l'infection virale. Conséquemment, la prolifération des lymphocytes $\mathrm{T} \mathrm{CD} 8^{+}$spécifiques au virus fut inhibée de près de $90 \%$ dans les ganglions lymphatiques au jour 5 post-infection, ce qui s'est traduit par une inhibition de plus de $50 \%$ de l'accumulation des cellules totales dans les poumons au jour 5 post-infection, et des cellules $\mathrm{T} C \mathrm{CD} 8^{+}$spécifiques au virus au jour 6 post-infection. Nous concluons que l'administration locale d'un agoniste des récepteurs de la S1P a le potentiel d'interférer avec les mécanismes classiques impliqués dans le développement de la réponse immunopathologique au virus de l'influenza.

\section{7}

\section{NEW INSIGHT INTO THE REGULATION OF RESPIRATORY SYNCYTIAL VIRUS-INDUCED PROINFLAMMATORY CYTOKINE RESPONSE}

F Yoboua, A Martel, A Duval, N Grandvaux

CRCHUM and Department of Biochemistry, Faculty of Medicine, Université de Montréal, Montréal, QC

BACKGROUND: Respiratory Syncytial Virus (RSV) is responsible for acute respiratory illness in children and elderly, such as bronchiolitis and pneumonia. RSV triggers an exacerbated production of proinflammatory cytokines in the airways that largely contributes to the development of these pathologies. The NF-kB transcription factor is a major regulator of proinflammatory cytokine and chemokine genes regulation. Surprisingly, the RSV-mediated activation of NF-KB in airway epithelial cells is far from being characterized.

PURPOSE: To characterize the molecular mechanisms involved in RSVmediated activation of NF-kB activation.

METHODS: We recently demonstrated that besides the well-characterized IkB $\alpha$-dependent pathway, phosphorylation of p65 at Ser536 is an essential event regulating RSV-mediated NF-kB activation. Using RNAi and pharmacological inhibitor, we now demonstrate that RSV sensing by the RIG-I cytoplasmic receptor triggers a signaling cascade involving the CARDIF and TRAF6 adaptors that ultimately leads to p65ser536 phosphorylation by the IKK $\beta$ kinase. Using antioxidant and RNAi strategies, we previously revealed that a NOX2-containing NADPH oxidase acts upstream of both the phosphorylation of IKB $\alpha$ at Ser32 and of p65 at Ser536 in A549 and Normal Human Bronchial Epithelial Cells. Here, we demonstrate that inhibition of NOX2 significantly decreases IKK $\beta$ activation. Taken together, our data identified a new RIG-I/CARDIF/TRAF6/ p65Ser536 pathway placed under the control of NOX2 that is essential for early proinflammatory cytokines expression regulation in the context of RSV infection.

\section{8}

\section{L'ACTIVATION DE LA RÉPONSE IMMUNE PULMONAIRE INNÉE PAR SACCHAROPOLYSPORA RECTIVIRGULA PROTÈGE CONTRE UNE INFECTION VIRALE CHEZ LA SOURIS}

M Girard, E Israël-Assayag, Y Cormier

Centre de recherche de I'Institut universitaire de cardiologie et de pneumologie de Québec, Québec, QC

PROBLÉMATIQUE: Le Saccharopolyspora rectivirgula (SR) est un actinomycète pouvant causer le Poumon du fermier, une forme d'alvéolite allergique extrinsèque. Des inhalations répétées de SR causent une réponse immune caractérisée par une neutrophilie précédant un influx de lymphocytes activés, au niveau des poumons. La plupart des individus et des animaux exposés à ce contaminant environnemental demeurent asymptomatiques et deviennent tolérants aux antigènes du SR. Nous nous sommes interrogés sur les effets que cette réponse immune pouvait avoir sur les défenses pulmonaires contre une infection virale chez la souris.

MÉTHODES: Des souris C57Bl/6 ont reçu des instillations intranasales d'un lysat de SR pendant différentes périodes de temps avant d'être infectées par une dose sub-léthale du virus Sendai. Des comptes cellulaires et différentiels, des études histopathologiques et des titrations de virus pulmonaires ont été effectués 6 et 9 jours post-Sendai. Le nombre requis d'instillations de même que la durée de la protection induite par le SR ont aussi été déterminés.

RÉSULTATS: L'administration de SR avant une infection virale diminue le nombre de cellules pulmonaires inflammatoires $(0,31 \times 10(6)$ vs $1,99 \times 10(6))$, les dommages pulmonaires engendrés de même que le nombre de particules virales dans le poumon (3,53 PFU vs $9.97 \mathrm{PFU}$ ) lorsqu'une seule dose de SR est donnée 24 heures avant le virus Sendai. L'inflammation induite par le SR est complètement disparue après 7 jours.

CONCLUSIONS: L'administration d'un lysat de SR induit une réponse immune innée protective et non-spécifique et représente une façon sécuritaire et efficace de prévenir les infections virales pulmonaires. 
39

\section{NEW MODELS OF IMMUNE SUSCEPTIBILITY TO RESPIRATORY PATHOGENS GENERATED USING ENU CHEMICAL MUTAGENESIS}

EI Lafferty ${ }^{1,2}$, I Angers ${ }^{1,2}$, SF Carroll ${ }^{1,2}$, SM Vidal ${ }^{1}$, ST Qureshi ${ }^{1,2}$ The Centre for the Study of Host Resistance - ${ }^{1}$ McGill University; ${ }^{2}$ McGill University Health Centre Research Institute, Montreal, QC BACKGROUND: Respiratory infections cause 3.98 million deaths annually and represent the most common cause of death globally. A precise understanding of the immune response against respiratory pathogens is an important step towards the development of novel treatment methods that reduce the burden of human respiratory disease. Chemical mutagenesis of mice with $\mathrm{N}$-ethyl $\mathrm{N}$-nitrosourea (ENU) is a new method to functionally characterize genes of the host immune response. This phenotype-driven forward genetic approach creates random mutations in the mouse genome and is a promising approach to identify and analyze the role of specific genes in host resistance against infectious diseases. Our group has used ENU mutagenesis to create a novel mutation that alters innate immunity, which we have called 'B04-3'.

PURPOSE: To characterize the role of the B04-3 mutation in the context of the immune response to respiratory pathogens and showcase ENU mutagenesis as an effective method to provide new insight into host immunity against respiratory pathogens.

METHODS: B04-3 mutant characterization - in vitro stimulation of splenocytes with synthetic TLR ligands with measurement of TNF- $\alpha$ and IL-6 to classify the affected immune pathways. Susceptibility characterization in vivo evaluation of differential survival between wildtype (C57BL/6J) and B04-3 mutant mice infected intratracheally with Streptococcus pneumoniae $\left(10^{6} \mathrm{cfu} /\right.$ mouse $)$ and influenza A virus $\left(5 \times 10^{3} \mathrm{pfu} / \mathrm{ml}\right)$.

FINDINGS: B04-3 mutant mice show reduced in vitro and in vivo inflammatory responses to pathogen challenge. Chemical mutagenesis is a promising method to characterize novel pathways of immunity against respiratory pathogens.

\section{0}

\section{LE DOUBLE VISAGE DES BACTÉRIES PATHOGÈNES OPPORTUNISTES DU GENRE BURKHOLDERIA}

SJ Charette ${ }^{1,2}$, L Vial ${ }^{3}$, MC Groleau ${ }^{3}$, MG Lamarche ${ }^{3}$, G Filion ${ }^{1,2}$, J Castonguay-Vanier ${ }^{3}$, V Dekimpe ${ }^{3}$, F Daigle $^{4}$, E Déziel $^{3}$

${ }^{1}$ Centre de recherche de I'Institut univesite de cardiologie et de pneumologie de Québec; ${ }^{2}$ Institut de biologie intégrative et des systèmes, Université Laval, Québec; ${ }^{3}$ INRS-Institut Armand Frappier; ${ }^{4}$ Département de microbiologie et immunologie, Université de Montréal, Montreal, QC

Les membres du complexe Burkholderia cepacia (Bcc), tels que B. ambifaria, sont des bactéries efficaces pour promouvoir la croissance des plantes. Cependant, plusieurs souches de Bcc peuvent également causer de graves infections respiratoires chez les personnes souffrant de fibrose kystique (FK). Dans la présente étude, nous dévoilons les premiers éléments sur le rôle de la variation de phase chez B. ambifaria pouvant expliquer le lien entre les souches infectieuses de Bcc et celles retrouvées dans l'environnement. HSJ1 est un isolat de B. ambifaria provenant d'un patient FK qui génère des variants stables de façon spontanée et indépendante des conditions de culture. Une analyse phénotypique a révélé que la transition de type sauvage à type variant affecte l'expression de plusieurs facteurs de virulence putatifs. En utilisant différents modèles d'infection dont des macrophages et l'amibe Dictyostelium discoideum, il a été possible de montrer que le type sauvage est plus virulent que le type variant. A l'inverse, le variant de phase de l'isolat HSJ1 est plus concurrentiel à coloniser les racines des plantes que le type sauvage. En outre, seuls les isolats cliniques de B. ambifaria peuvent générer des variants de phase, et que ces variants ont montré des phénotypes similaires à ceux observés pour le variant de HSJ1. Enfin, les isolats environnementaux de B. ambifaria montrent des traits qui sont caractéristiques des variants dérivés des isolats cliniques. Notre étude suggère donc que B. ambifaria utilise la variation de phase pour s'adapter à des environnements radicalement différents.

\section{1}

\section{ARCHAEBACTÉRIES : AGENT MÉCONNU DES BIOAÉROSOLS}

Pascale Blais Lecours ${ }^{1}$, M. Veillette ${ }^{1}$, Y. Cormier ${ }^{1}$, R Forster ${ }^{3}$, C Duchaine ${ }^{1,2}$

${ }^{1}$ Institut universitaire de cardiologie et de pneumologie de Québec; ${ }^{2}$ Université Laval département de biochimie et de microbiologie, Montreal, QC; ${ }^{3}$ Agriculture Agri-Food Canada, Ottawa, ON

Les installations agricoles sont hautement contaminées par les bioaérosols. De plus, il est déjà connu que plusieurs maladies respiratoires sont fréquemment rencontrées dans les milieux de travail agricoles en raison de ces bioaérosols. Nous devons répondre aux questions quant à la compréhension de la relation entre la poussière organique et les maladies pulmonaires. Notre équipe a récemment décrit une quantité étonnamment élevée d'archaebactéries dans l'air des porcheries. Les objectifs du projet sont : 1) caractériser l'air des fermes laitières et des usines d'épuration d'eaux usées et leur contenu en archaebactéries ; 2) vérifier la sensibilité des travailleurs de porcheries aux archaebactéries et 3) vérifier si les archaebactéries pourraient causer un rôle dans l'inflammation pulmonaire. Les méthodes utilisées comprendront la biologie moléculaire, des techniques immunologiques ainsi que deux modèles murins bien connus pour répondre au HP et aux endotoxines. Cette étude pourrait révéler un nouvel agent immunogène et ouvrir la voie à une nouvelle thématique de recherche.

\section{2}

PRESENCE DE PATHOGENES ZOONOTIQUES ET DE GENES DE RESISTANCE A LA TETRACYCLINE DANS LA FLORE NASOPHARYNGEE DE PRODUCTEURS DE PORCS

V Létourneau ${ }^{1}$, A Mériaux ${ }^{2}$, D Massé ${ }^{3}$, Y Cormier ${ }^{1,2}$,

C Duchaine ${ }^{1,2}$

${ }^{1}$ Université Laval, Québec; ${ }^{2} \mathrm{CRIUCPQ}$, Québec; ${ }^{3}$ Agriculture et Agroalimentaire Canada, Lennoxville, QC

INTRODUCTION : Depuis une vingtaine d'années, la production porcine canadienne s'intensifie et s'industrialise. Les animaux sont maintenant engraissés dans de larges bâtiments fermés. L'air ambiant, à l'intérieur des bâtiments, contient d'importantes concentrations d'aérosols qui sont principalement issus des lisiers des porcs. Les lisiers de porcs sont une source importante de pathogènes zoonotiques et de bactéries résistantes à la tétracycline. BUT : Analyser la flore nasopharyngée de producteurs de porcs afin d'évaluer l'exposition des travailleurs à des pathogènes zoonotiques et à des bactéries résistantes à la tétracycline aérosolisés.

METHODES : Le nasopharynx de 34 producteurs de porcs et de contrôles non exposés a été échantillonné à l'aide d'un écouvillon en alginate de calcium. L'ADN total des écouvillons a été extrait puis l'ARNr $16 \mathrm{~S}$ de Campylobacter, C. perfringens, Enterococcus, E. coli et de Y. enterocolitica et les gènes tet $\mathrm{A} / \mathrm{C}$, tet $\mathrm{G}$ et RPPs ont été détectés par PCR quantitatif. RESULTATS : Treize flores nasopharyngées de producteurs de porcs étaient contaminées par Enterococcus, 10 par E. coli et une par Y. enterocolitica. Aucune flore nasopharyngée des contrôles n'était positive pour les pathogènes zoonotiques étudiés. Le gène de résistance à la tétracycline tetG a été retrouvé dans six flores nasopharyngées de producteurs de porcs. Aucun gène de résistance à la tétracycline n’a été détecté dans les flores nasopharyngées des contrôles.

CONCLUSION : Les producteurs de porcs sont exposés à des aérosols contaminés par des pathogènes zoonotiques et des bactéries résistantes à la tétracycline, ces bactéries pouvant coloniser le nasopharynx.

\section{3}

\section{TROUBLES DU SOMMEIL CHEZ LES CANADIENS SOUFFRANT D'ASTHME, DE BRONCHITE CHRONIQUE OU DE BRONCHOPNEUMOPATHIE CHRONIQUE OBSTRUCTIVE}

A Des Cormiers, LP Boulet

Centre de recherche de I'Institut universitaire de cardiologie et de pneumologie de Québec, Québec, QC

PROBLÉMATIQUE : L'asthme (A), la bronchite chronique (BC) et la bronchopneumopathie chronique obstructive (BPCO) sont des maladies 
respiratoires qui peuvent être associées aux troubles du sommeil. But : Dans la population canadienne, comparer la prévalence de problèmes associés au sommeil chez les individus souffrant d'asthme, de bronchite chronique ou de BPCO. Méthodes : Cette étude transversale a été conduite à partir du fichier de microdonnées à grande diffusion de l'Enquête sur la santé dans les collectivités canadiennes (ESCC) cycle 1.1 2000-2001. Un échantillon de 133000 personnes a été sélectionné et représentait $98 \%$ de la population canadienne de plus de 12 ans. Résultats : Une plus grande fréquence de problèmes à s'endormir ou à rester endormi la plupart du temps a été observée chez les sujets rapportant de l'asthme (19,1\%), des bronchites chroniques $(29,7 \%)$ ou des $\mathrm{BPCO}(30,9 \%)$ que dans la population générale $(12,8 \%)$. Une grande proportion des gens rapportant au moins une de ces maladies disent avoir un sommeil réparateur la plupart du temps (A : $50,7 \%$; BC : 42,1\%; BPCO : 45,1\%) comparativement à 62,3\% de ceux ne rapportant aucune de ces pathologies. Une différence a été observée concernant la difficulté à rester éveillé la plupart du temps ( $\mathrm{A}: 8,3 \%$; BC : 10,5\% ; BPCO : $11,0 \%)$ comparé au reste des Canadiens $(5,7 \%)$. On remarque que la fréquence de fatigue chronique était également plus élevée (A : $1,7 \%$; BC : 3,2\% ; BPCO : 5,2\%) que dans le reste de la population $(0,8 \%)$. Conclusion : L'asthme, la bronchite chronique et la BPCO entraînent une augmentation de la prévalence de troubles du sommeil chez les sujets atteints de ces maladies.

\section{4}

\section{DIFFÉRENCES ENTRE MASQUES NASAL ET FACIAL DANS LE TRAITEMENT DE L'APNÉE DU SOMMEIL PAR PRESSION POSITIVE CONTINUE}

\section{Kaminska ${ }^{1}$, A Montpetit ${ }^{2}$, A Mathieu ${ }^{3}$, V Jobin ${ }^{3}$, F Bellemare ${ }^{3}$,} F Morisson $^{2}$, P Mayer ${ }^{3}$

${ }^{1}$ Centre Universitaire de Sante McGill; ${ }^{2}$ Université de Montréal; ${ }^{3}$ Centre Hospitalier de I'Université de Montréal, Montreal, QC

Dans le traitement de l'apnée du sommeil par pression positive continue (PPC), les masques nasaux et faciaux sont souvent utilisés de façon interchangeable. Cependant, en clinique, l'efficacité des deux types de masques ne semble pas toujours équivalente, et très peu d’études ont comparé les deux types de masques pour le traitement de l'apnée du sommeil par PPC. L'objectif de cette étude était de comparer la PPC optimale appliquée par masque nasal ou facial en regard de la correction des événements respiratoires obstructifs.

Les sujets ont été recrutés à la clinique du sommeil de l'Hôpital Hôtel-Dieu de Montréal. Chacun a passé une polysomnographie thérapeutique avec sonde œsophagienne où la PPC a été titrée avec chaque masque, en alternant le premier type de masque pour chaque sujet consécutif.

Huit sujets ( 2 femmes et 6 hommes) ont été étudiés, dont le niveau moyen de $\mathrm{PPC}$ efficace par masque nasal était de $9.9 \mathrm{cmH}_{2} \mathrm{O}\left(5\right.$ à $\left.15 \mathrm{cmH}_{2} \mathrm{O}\right)$. Chez seulement 2 sujets la pression efficace était équivalente par les 2 masques. Chez 4 sujets, des événements obstructifs persistaient avec le masque facial à la pression maximale $\left(20 \mathrm{cmH}_{2} \mathrm{O}\right)$. Chez les 2 derniers, une hausse de pression de 5 et $8 \mathrm{cmH}_{2} \mathrm{O}$ respectivement était nécessaire avec le masque facial comparé au nasal.

La pression optimale de traitement de l'apnée obstructive par PPC avec un masque facial n'est pas toujours équivalente à celle du masque nasal. Ceci peut avoir d'importantes implications cliniques. Les mécanismes possibles pouvant expliquer ce phénomène sont : l'augmentation potentielle de la résistance des voies aériennes supérieures, l'augmentation de la fuite et l'instabilité ventilatoire associées au masque facial.

\section{5}

\section{PEAK COUGH FLOW RATES (PCFR) IN CHILDREN WITH NEUROMUSCULAR DISEASES AND SEVERE LUNG IMPAIRMENT}

\section{TTD Nguyen, F Marquis, G D'Anjou, L Colombini, S Laberge,} JG Lapierre

Centre de Réadaptation Marie-Enfant, CHU Ste-Justine, Université de Montréal, Montréal, QC

INTRODUCTION: Respiratory disease is a major cause of morbidity and mortality in patients with neuromuscular disease. Inefficient cough is a common problem in this population, leading to decreased clearance and recurrent respiratory infections. The ability to clear secretions from the respiratory tract has been shown to correlate with peak cough flows. OBJECTIVES: To determine the peak cough flow rates in children with neuromuscular diseases and severe lung impairment. To compare peak cough flow rates between patients with home mechanical ventilation (HMV) and patients without HMV. To investigate the relationship between peak cough flow rates (PCFR), forced vital capacity (FVC), peak expiratory flow rate (PEFR), maximum expiratory pressure (MEP) and maximum inspiratory pressure (MIP).

MATERIALS AND METHODS: The sample consisted of 24 children with neuromuscular disease (Duchenne Muscular Dystrophy 10, Spinal Muscular Atrophy 5, others 10) whose forced vital capacity values were below $50 \%$ of predicted. All respiratory assessments were done in clinical stable condition. FVC, PEFR, MEP and MIP were measured according to ATS standard guidelines. Predicted values of pulmonary function were derived from published data. PCFR was measured by having the patient cough forcefully through a face mask and a peak flow meter. The highest value of three maneuvers was recorded. The predicted peak cough flow rates (\%PCFR) for height were obtained using the reference values for PCFR in the pediatric population by Bianchi et al .

\section{6}

RÉGULATION EN PRESSION DURANT L'EXPIRATION SUR UN PROTOTYPE DE RESPIRATEUR LIQUIDIEN TOTAL : TRANSPOSITION ET ADAPTATION D'UN MODE UTILISÉ EN VENTILATION MÉCANIQUE CONVENTIONNELLE (VMC) R Robert ${ }^{1}$, A Beaulieu ${ }^{1}, \mathrm{O}$ Avoine $^{2}$, H Walti ${ }^{2}$, P Micheau ${ }^{1}$ ${ }^{1}$ Inolivent, Département de génie mécanique, Université de Sherbrooke, ${ }^{2}$ Inolivent, Département de pédiatrie, Centre Hospitalier Universitaire de Sherbrooke, Sherbrooke, QC

La ventilation liquidienne totale consiste à remplir totalement les poumons de liquide respirable (un perfluorocarbone). L'insertion et le retrait d'un volume courant sont réalisés à l'aide d'un respirateur liquidien.

Le prototype de respirateur liquidien Inolivent-4, est issu d'un projet conjoint entre chercheurs en génie mécanique et en pédiatrie. L'objectif de l'étude ici rapportée était de concevoir un contrôleur capable d'effectuer une ventilation contrôlée en pression (mode PCV), afin de facilité son utilisation.

Deux contrôleurs distincts ont été implantés pour réguler la pression de fin d'expiration (PEEP) et la pression trachéale durant l'expiration. Contrairement à la VMC, une pression de référence (Pref) inférieure à la PEEP est maintenue constante dans les voies respiratoires et la PEEP est ajustée à chaque cycle en modifiant le volume pulmonaire.

Le fonctionnement a été validé in-vitro et in-vivo sur cinq agneaux à poumons sains, selon le protocole approuvé par notre comité institutionnel de protection des animaux. Les agneaux ( $<4$ jours, $2.5-5.0 \mathrm{~kg}$ ) ont été ventilés à des volumes-minute $(V \min )$ de $120,140,160$ et $180 \mathrm{ml} / \mathrm{min} / \mathrm{kg}$, à une fréquence de 5.0-5.5 min-1, une PEEP de référence de $5 \mathrm{cmH}_{2} \mathrm{O}$ et une Pref de -2 à $-30 \mathrm{cmH}_{2} \mathrm{O}$.

Sur l'ensemble des données in-vivo recueillies aux différentes Vmin, la pression moyenne durant l'expiration varie de $\pm 2 \mathrm{cmH}_{2} \mathrm{O}$ autour de la référence et la PEEP dévie d'au plus $2 \mathrm{cmH}_{2} \mathrm{O}$. Les gaz sanguins montrent que ces performances assurent une ventilation adéquate $\left(\mathrm{PaO}_{2}=266 \mathrm{mmHg}, \mathrm{PaCO}_{2}\right.$ $=40.9 \mathrm{mmHg}, \mathrm{pH}=7.309$ moyen pour $\mathrm{Vmin}$ de $180 \mathrm{ml} / \mathrm{min} / \mathrm{kg}$ ), sans collapsus expiratoires.

Ce mode facilitera l'utilisation clinique du respirateur.

\section{7}

\section{ÉVALUATION DE LA FAISABILITÉ, DE L'EFFICACITÉ ET DE LA TOLÉRANCE DU MODE NAVA EN PÉDIATRIE}

Alice Bordessoule ${ }^{1}$, A Eddington ${ }^{1}$, Jennifer Beck ${ }^{2}$, Philippe Jouvet ${ }^{1}$. ${ }^{1}$ Pediatric Intensive Care, Sainte-Justine Hospital, University of Montreal, Monteal, QC; ${ }^{2}$ Keenan Research Centre of the Li Ka Shing Knowledge Institute of St Michael's Hospital, Toronto, ON CONTEXTE: Afin d'améliorer la synchronisation patient-respirateur et de délivrer une assistance respiratoire proportionnelle à l'effort du patient, un nouveau mode de ventilation a été développé : la ventilation assistée 
ajustée au signal neural (NAVA). Nous avons évalué le mode NAVA chez des enfants en phase de sevrage.

OBJECTIFS: Évaluation de la faisabilité, de l'efficacité et de la tolérance du mode NAVA en pédiatrie.

MÉTHODES: Tous les enfants hospitalisés dans le service de réanimation pédiatrique de l'hôpital Sainte Justine ont été sélectionnés de Février 2008 à Avril 2009. Ils répondaient aux critères suivants: i) âge $<1$ an, ii) ventilé en mode assisté, iii) pression de plateau (au dessus de la PEEP) $<22 \mathrm{cmH}_{2} \mathrm{O}$ et iv) $\mathrm{PEEP} \leq 6 \mathrm{cmH}_{2} \mathrm{O}$. Après inclusion, un tube nasogastrique avec électrodes d'enregistrement de l'activité électrique du diaphragme (EAdi) étaient insérés. Les enfants étaient ventilés selon la séquence suivante: 30 minutes avec les paramètres initiaux, 5 heures en NAVA, 30 minutes en mode assisté contrôlé (PAC) et 30 minutes en mode aide inspiratoire (AI). Les signes vitaux, les paramètres ventilatoires et l'EAdi étaient enregistrés. L'efficacité était jugée sur la synchronisation patient-respirateur (index d'asynchronie = délai de déclenchement + délai de trigger expiratoire / temps total neural). La tolérance était évaluée par la fréquence respiratoire, le volume courant, la saturation de l'hémoglobine en oxygène $\left(\mathrm{SO}_{2}\right)$ et le $\mathrm{CO}_{2}$ expiré.

RÉSULTATS: Dix patients ont été inclus (âgés de $4.3 \pm 2.4$ mois et pesant $5.9 \pm 2.2 \mathrm{~kg}$ ). L'EAdi était correctement détecté durant le mode NAVA chez tous les patients ayant la sonde en position nasogastrique. Chez un patient ayant la sonde positionnée en oro-gastrique la détection de l'EAdi était très fluctuante nécessitant le relais par voie naso-gastrique. Après titration, la $\mathrm{PEEP}$ et le niveau de NAVA étaient de $4.8 \pm 0.7 \mathrm{cmH}_{2} \mathrm{O}$ et $1.9 \pm 2.05 \mu$ Volt $/ \mathrm{cmH}_{2} \mathrm{O}$ respectivement. La synchronisation patient-respirateur était meilleure durant le mode NAVA comparée aux modes PAC et AI: L'index d'asynchronie était de $10.7 \pm 3.5 \%$ en NAVA vs $23.4 \pm 11.3 \%$ en PAC vs $24.9 \pm 9.2 \%$ en PS $(\mathrm{p}<0.01)$. Le délai de déclenchement était significativement plus court en mode NAVA $(97.5 \pm 19 \mathrm{~ms})$ comparativement à la PAC $(202 \pm 81 \mathrm{~ms}$; $\mathrm{p}=0.001)$ et à l'AI $(137 \pm 26 \mathrm{~ms} ; \mathrm{p}=0.003)$. Le délai de trigger expiratoire était significativement plus court en NAVA $(46 \pm 22 \mathrm{~ms})$ vs en PAC (168 $\pm 68 \mathrm{~ms} ; \mathrm{p}<0.05)$ vs en AI $(139 \pm 43 \mathrm{~ms} ; \mathrm{p}<0.05)$. La tolérance était bonne en NAVA sans différence significative avec les modes PAC et AI pour la fréquence respiratoire, la $\mathrm{SO}_{2}$ et le $\mathrm{CO}_{2}$ expiré. Nous avons observés des augmentations importantes de pression de plateau durant les soupirs.

CONCLUSIONS : Le mode NAVA est faisable chez les enfants de moins d'un an à condition que la sonde d'enregistrement de l'EAdi soit positionnée en naso-gastrique. Ce mode est bien toléré et améliore la synchronisation patient-respirateur comparé aux modes conventionnels.

\section{8}

\section{NEONATAL TOTAL LIQUID VENTILATION: IS LOW} FREQUENCY FORCED OSCILLATION TECHNIQUE SUITABLE FOR RESPIRATORY MECHANICS ASSESSMENT?

D Bossé, A Beaulieu, O Avoine, P Micheau, J-P Praud, H Walti Université de Sherbrooke, Sherbrooke, QC

OBJECTIVE: This study aimed to implement low-frequency forced oscillation technique (LFFOT) in neonatal total liquid ventilation (TLV) and to provide the first insight into respiratory impedance under this new modality of ventilation.

METHODs: 13 newborn lambs weighing $2.5 \pm 0.4 \mathrm{~kg}$ were premedicated, intubated, anesthetized, and then placed under TLV using a speciallydesigned liquid ventilator and a perfluorocarbon. The respiratory mechanics measurements were started immediately after TLV initiation. 3 blocks of measurements were first performed: one during initial respiratory system adaptation to TLV, followed by 2 others series during steady state conditions. Lambs were then divided into 2 groups prior to undergoing another 3 blocks of measurements: the first group received a 10-min i.v. infusion of salbutamol $(1.5 \mu \mathrm{g} / \mathrm{kg} / \mathrm{min})$ after continuous infusion of methacholine $(9 \mu \mathrm{g} / \mathrm{kg} / \mathrm{min})$ while the second group were chest-strapped. Respiratory impedance was measured using serial single-frequency tests at frequencies ranging between 0.05-2 $\mathrm{Hz}$ and then fitted with a constant-phase model. $0.2 \mathrm{~Hz}$ harmonic test signals were also launched every $10 \mathrm{~min}$ throughout the measurement protocol.

RESULTS: Airway resistance and inertance were starkly increased in TLV compared to gas ventilation with a resonant frequency $\leq 1.2 \mathrm{~Hz}$. $0.2 \mathrm{~Hz}$ resistance and reactance were sensitive to bronchoconstriction and dilation as well as during compliance reduction.
CONCLUSIONS: We report successful implementation of LFFOT to neonatal TLV and present the first insight into respiratory impedance under this new modality of ventilation. We show that LFFOT is an effective tool to track respiratory mechanics under TLV.

\section{9}

\section{IMPACT DU TRAITEMENT DU SYNDROME D'APNÉE/ HYPOPNÉE DU SOMMEIL DANS LA SCLÉROSE EN PLAQUES}

I Côté, DA Trojan, D Weiss, M Kaminska, D DaCosta, A Bar-Or, A Benedetti, Y Lapierre, D Arnold, A Robinson, K Schwartzman, RJ Kimoff

Département de Neurologie et Neurochirurgie, Institut

Neurologique de Montréal; Division de Pneumologie, CUSM;

Division d'épidémiologie clinique, CUSM, Montréal, QC

CONTEXTE: La fatigue est un symptôme prévalent et incapacitant dans la SP. Dans une étude récente chez 62 patients SP, nous avons trouvé un lien significatif entre le syndrome d'apnée/hypopnée du sommeil (SAHS) et la fatigue sévère.

OBJECTIFS: Étudier l'impact du traitement du SAHS sur la fatigue ainsi que sur la somnolence, la qualité de vie et du sommeil chez les patients SP. MÉTHODES: Des 62 patients étudiés avec polysomnographie nocturne et questionnaires de base, 33 sujets ont actuellement complété des questionnaires de suivi après $\geq 3$ mois soient les: multidimensional fatigue inventory (MFI), fatigue severity scale (FSS), Epworth sleepiness scale (ESS), Pittsburgh sleep quality index (PSQI) et Short Form (36) Health survey (SF 36).

RÉSULTATS: Des 33 patients, 9 ont un SAHS traité (CPAP: $4.8 \pm 1.6 \mathrm{~h} / \mathrm{N}$ ), 5 SAHS ont refusé le traitement, 7 SAHS légers sont traités de façon conservatrice et 12 n'avaient pas de troubles du sommeil (groupe témoin non traité, $\mathrm{n}=24$ ). Les valeurs de base étaient similaires pour les 2 groupes. Après $\geq 3$ mois, chez les patients traités, le MFI, l'ESS et le PSQI se sont améliorés significativement $(\mathrm{p}<0.05)$ tandis que pour le FSS $(\mathrm{p}=0.05)$. À l'opposé, pour le groupe non traité, bien que le PSQI se soit amélioré légèrement $(\mathrm{p}<0.05)$, les autres mesures n'ont pas changé.

CONCLUSION: Dans ces analyses préliminaires d'une étude en cours, le traitement du SAHS chez les patients SP a un impact favorable sur la fatigue de même que sur la somnolence et la qualité du sommeil. Subventionné par la Société de Scléroses en Plaques

\section{0}

\section{WEANING CHILDREN FROM MECHANICAL VENTILATION WITH A COMPUTER-DRIVEN EXPLICIT PROTOCOL: A RANDOMIZED CLINICAL TRIAL}

Philippe Jouvet ${ }^{1}$,Valerie Payen ${ }^{1}$, France Gauvin ${ }^{1}$, Miriam Santschi ${ }^{2}$, Allen Eddington ${ }^{1}$, Jacques Lacroix ${ }^{1}$

${ }^{1} \mathrm{CHU}$ Sainte-Justine, University of Montreal, Montreal; ${ }^{2} \mathrm{CHU}$ Sherbrooke, Sherbrooke, QC

Duration of weaning from mechanical ventilation (MV) may be decreased by the use of written protocols in adults but not in children. We assessed whether a computer-driven explicit computerized protocol can decrease duration of weaning from MV when compared to usual care, in children. METHODS: We conducted a single center randomized clinical trial in a tertiary care university hospital. Mechanically ventilated children aged between 2 and 17 years with a positive pressure support test and no inotropes were included in a RCT. After randomization, children were weaned either by usual care (control group, $\mathrm{n}=15$ ) or by a computer-driven explicit protocol which interprets clinical data in real-time and controls pressure support levels: Smartcare ${ }^{\circledR}$, Drager Medical (“closed-loop” group, n=15). Weaning duration until 1 st extubation was the primary outcome. For comparison, a Mann Whitney test was employed.

RESULTS: Patients characteristics at inclusion were similar. The median duration of weaning was $21 \mathrm{hr}$ (25th-75th IQ: 17hr; 46hr) in "closed loop" group and $90 \mathrm{hr}$ (25th-75th IQ: 30hr; 194hr) in control group, p=0.007. Total duration of MV was also reduced: $144 \mathrm{hr}$ vs $234 \mathrm{hr}$ ( $\mathrm{p}=0.16$ ), respectively. In both groups, 1 patient was reintubated within $48 \mathrm{hr}$ and 2 patients had non invasive ventilation, after the 1 st extubation. 
CONCLUSIONS: The computer-driven explicit protocol significantly reduced the duration of weaning when compared to usual care without increase of weaning failure rate. A multicenter trial is mandatory to confirm these results in a larger panel of pediatric intensive care units.

FINANCIAL SUPPORT: Réseau en santé respiratoire du FRSQ. ClinicalTrials.gov: NCT00678912.

\section{1}

\section{TREATMENT OF ACTIVE TUBERCULOSIS IN PATIENTS} WITH HIV: A SYSTEMATIC REVIEW AND META-ANALYSIS

Faiz A Khan', Jessica Minion', Madhukar Pai ${ }^{2}$, Sarah Royce ${ }^{3}$, William Burman ${ }^{4}$, Anthony D Harries ${ }^{5}$, Dick Menzies ${ }^{1}$

${ }^{1}$ Montreal Chest Institute, McGill University Health Centre;

${ }^{2}$ Department of Epidemiology, Biostatistics \& Occupational Health, McGill University, Montreal, QC; ${ }^{3}$ Univesity of California,

San Francisco; ${ }^{4}$ Denver Public Health, Denver, USA; ${ }^{5}$ IUTLD Paris, France \& London School of Hygiene \& Tropical Medicine, United Kingdom

BACKGROUND: Patients with HIV-related tuberculosis (TB) have an increased risk of death, treatment failure, and relapse.

METHODS: A systematic review and meta-analysis of randomized controlled trials and cohort studies addressing treatment of active TB in HIV. positive patients. Studies were included if the initial TB diagnosis, failure and/or relapse were microbiologically confirmed, and patients received standardized rifampin or rifabutin containing regimens. Pooled cumulative incidence of treatment failure, death during treatment, and relapse were calculated using random-effects models. Multivariable meta-regression was performed using negative binomial regression.

RESULTS: After screening 5158 citations, 6 randomized trials and 21 cohort studies were included. Relapse was more common with regimens utilizing 2 months rifamycin [adjusted incidence rate ratios: 3.6 (95\% confidence interval: $1.1,11.7)$ ], than with regimens utilizing rifamycin for at least 8 months. Compared to daily therapy in the initial phase, thrice weekly therapy initially was associated with higher rates of failure [aIRR: $4.0(1.15,10.4)$ ] and relapse [aIRR: $4.8(1.8,12.8)]$. There were trends toward higher relapse rates if rifamycins were used for only six months compared to eight months or more [aIRR $2.4(0.8,7.4)]$, or if antiretroviral therapy was not used [aIRR $3.5(0.5,26)]$.

CONCLUSIONS: This review raises serious concerns regarding the optimal duration and dosing schedule for treatment of HIV-TB. These concerns cannot be properly addressed with the currently available evidence. Adequately powered randomized trials are urgently needed to address these issues.

\section{2}

\section{LONG-TERM OUTCOMES OF PREMATURE BIRTH \& THE HEALTHCARE UTILIZATION OF INFANTS WITH BRONCHOPULMONARY DYSPLASIA}

\section{J Landry, D Menzies}

Respiratory Epidemiology \& Clinical Research Unit,

McGill University, Montreal, QC

RATIONALE: Bronchopulmonary dysplasia (BPD) is a chronic lung disease that affects premature babies and contributes to their morbidity and mortality. Improved survival of very immature infants has led to increased numbers of young adults with this disorder. This increase places a heavy burden on health resources and the natural history of the disease once adulthood is reached is poorly described.

METHODS: Design: This study was performed using a retrospective cohort design comparing BPD subjects and premature subjects with respiratory distress syndrome (RDS) but without subsequent BPD. Using databases provided by the Regie de l'Assurance-Maladie du Quebec (RAMQ), data on hospitalizations, diagnosis, medical and emergency room visits and medication use (drug type, dosage, quantity, duration and renewal pattern) along with their attributable costs were tabulated on all subjects.

RESULTS: This study provided 28 years of data on 776 subjects with BPD and 2669 premature with RDS (mean age in 2008 of 17.9 years). The longterm data showed, that among subjects born with BPD and having reached adulthood in 2008, 26.91\% were labelled as having asthma compared to $11.8 \%$ in the RDS group.

CONCLUSION: BPD has a long-term impact on healthcare utilization and medication use when compared to premature subjects without BPD. This may influence their health-related quality of life.

\section{3}

ÉVOLUTION PSYCHOLOGIQUE ET SOCIOPROFESSIONNELLE DES PERSONNES VUES POUR ASTHME PROFESSIONNEL PROBABLE À L'HÔPITAL DU SACRÉ-COEUR DE MONTRÉAL ENTRE 1997 ET 2007 : RÉSULTATS PRÉLIMINAIRES

G Moullec, J L'Archevêque, K Lavoie, D Gautrin, JL Malo, M Labrecque

Centre de Recherche de l'Hôpital du Sacré-Coeur de Montréal Centre Asthme et Travail, Montréal, QC

RATIONNEL: La reconnaissance du diagnostic d'asthme professionnel (AP) par la Commission de la Santé et Sécurité du Travail est souvent longue et exigeante pour le travailleur : de l'évaluation par les centres spécialisés jusqu'aux procédures d'indemnisation.

OBJECTIFS : Vérifier si l'évolution psychologique et socio-économique à long-terme des sujets est fonction du diagnostic posé lors de l'évaluation. Devis: Etude de cohorte rétrospective. Source des données: Base de données des 1141 sujets investigués pour AP probable, entre 1997 et 2007, avec un test de provocation bronchique spécifiqueà l'Hôpital du SacréCour de Montréal (HSCM). Mesures: Auto-questionnaires (par courriers postaux) évaluant l'état fonctionnel et psychologique (qualité de vieSF-36, symptômes d'anxiété et de dépression -Inventaires de Beck), suivis d'un entretien téléphonique recueillant des informations sur l'évolution socio-professionnelle et l'utilisation des services de soins dans l'année courante.

RÉSULTATS: A ce jour, 104 questionnaires et entretiens complétés: 36 sujets ayant reçu un diagnostic d'AP, 38 un diagnostic d'asthme personnel (APer), et 32 non asthmatiques (NA). Les NA ont des scores plus élevés aux dimensions 'vitalité' et 'changement de santé' du SF-36 comparés aux AP et APer. Les sujets AP ou APer ont un score de dépression plus élevé comparés au NA. Les sujets NA consultent plus leur médecin généraliste et spécialiste. La proportion de sujets sans emploi est supérieure chez les AP (45\%) comparés aux APers (40\%) et NA (33\%).

CONCLUSION: Cette étude nous renseigne sur la nécessité de dispositifs de suivi pour accompagner les travailleurs après l'annonce ou non du diagnostic d'AP.

\section{4}

\section{SLEEP-DISORDERED BREATHING IS ASSOCIATED WITH FATIGUE RATHER THAN EXCESSIVE SLEEPINESS IN MULTIPLE SCLEROSIS}

M Kaminska', D A Trojan², D Da Costa ${ }^{1}$, A Bar-Or², A Benedetti', Y Lapierre ${ }^{2}$, D L Arnold ${ }^{2}$, A Robinson ${ }^{2}$, A Venturini ${ }^{1}$, K Schwartzman ${ }^{1}$, R J Kimoff ${ }^{1}$

${ }^{1}$ McGill University Health Centre, Montreal; ${ }^{2}$ Montreal Neurological Institute, McGill University, Montreal, QC

Daytime sleepiness is the hallmark manifestation of sleep-disordered breathing (SDB). Fatigue is increasingly recognized to be associated with SDB as well, and is a frequent and disabling symptom of multiple sclerosis (MS). Because we have found SDB to be common in MS, we aimed to investigate its relationship to fatigue and sleepiness in this patient population.

Stable, ambulatory MS patients without known sleep disorders were recruited from a tertiary care center. They underwent overnight polysomnography and a multiple sleep latency (MSL) test. Subjective sleepiness was measured with the Epworth Sleepiness Scale (ESS) and fatigue with the Fatigue Severity Scale (FSS, score 1-7).

$62 \mathrm{MS}$ subjects were studied. Their mean apnea-hypopnea index (AHI) was 21.2/h (range 5.3/h to 68.4/h) and mean oxygen desaturation index (ODI) $0.9 / \mathrm{h}$ (range $0 / \mathrm{h}$ to $31.3 / \mathrm{h}$ ). The means $( \pm \mathrm{SD})$ were: FSS $5.1 \pm 1.6$, ESS $8.4 \pm 4.5$ and MSL $11.1 \pm 5.3 \mathrm{~min}$. Those with severe OSA $(\mathrm{AHI} \geq 30)$ had an odds ratio for severe fatigue (FSS $\geq 5$ ) adjusted for age, sex, BMI and disability, of 12.5 (95\% confidence interval 2.3 to 114 ). Odds ratios were 
not significant for subjective (ESS $\geq 11$ ) or objective sleepiness (MSL $\leq 5 \mathrm{~min}$ ). Compared with subjects with FSS $<5$, subjects with FSS $\geq 5$ had higher total and respiratory-related arousal indices $(43.6 / \mathrm{h} \pm 15.8$ vs. $34.9 / \mathrm{h} \pm 14.9$, $\mathrm{p}=0.03 ; 24.7 / \mathrm{h} \pm 14.2$ vs. $14.4 / \mathrm{h} \pm 8.5, \mathrm{p}=0.0007)$, while the non-respiratoryrelated arousal index $(18.9 / \mathrm{h} \pm 8.9$ vs. $20.5 / \mathrm{h} \pm 12.7, \mathrm{NS})$ and ODI $(3.8 / \mathrm{h} \pm 6.7$ vs. $3.4 / \mathrm{h} \pm 7.0, \mathrm{NS})$ were similar.

Severe SDB is associated with severe fatigue but not sleepiness in MS. The association appears to be explained primarily by respiratory-related arousals.

\section{5}

\section{CORRESPONDANCE ENTRE LES SYMPTÔMES RESPIRATOIRES ET LES RÉSULTATS DU TEST À LA MÉTACHOLINE}

M Lévesque, H Ghezzo, J L'Archevêque, JL Malo

Service de pneumologie, Hôpital du Sacré-Coeur de Montréal, Montréal, QC

INTRODUCTION: L'interprétation du test de provocation à la métacholine ne considère pas les symptômes pour lesquels le sujet est référé ou ceux ressentis au moment du test.

MÉTHODES: Analyse prospective des données de 400 sujets ayant subi un test de provocation à la métacholine et ayant répondu au questionnaire de l'étude.

RÉSULTATS: Le test de provocation bronchique à la métacholine reproduit les symptômes pour lesquels le sujet est référé avec une valeur prédictive positive (VPP) satisfaisante : dyspnée $84 \%$, toux $87 \%$, sifflements $81 \%$, oppression $72 \%(\mathrm{p}<0.001)$. Les symptômes pour lesquels le sujet est référé et ceux ressentis lors du test sont associés à un test de provocation positif, la VPP augmentant en fonction du niveau de la CP20 $(<2$, $<8$ et $\leq 16 \mathrm{mg} / \mathrm{ml}$ ). La perception globale ressentie par le sujet que le test reproduit ses symptômes est associée à un test positif $(\mathrm{CP} 20 \leq 16 \mathrm{mg} / \mathrm{ml})$ dans $48 \%(p=0.04)$ des cas. Par analyse mutlivariée, cette correspondance entre les symptômes justifiant la référence et ceux ressentis lors du test est significative chez les sujets plus jeunes (rapport de cotes RC: 0.99, IC95\% :0.97-1.00] $\mathrm{p}=0.06$ ), de sexe féminin (RC: 1.4 , IC95\% [0.97-2.24] p=0.07) et ayant une CP20 $\leq 16 \mathrm{mg} / \mathrm{ml}$ (RC: 1.43 ,IC95\% : 0.94-2.18] p=0.09).

CONCLUSION: Le test de provocation à la métacholine reproduit le plus souvent les symptômes pour lesquels le sujet est référé. Cette correspondance est associée à un test positif et est meilleure chez les jeunes et chez les femmes. L'interprétation du test à la métacholine semble donc plus satisfaisante si elle inclut la valeur de CP20 et la documentation des symptômes motivant la référence et lors du test.

\section{6}

CARACTÉRISTIQUES DES SUJETS INVESTIGUÉS POUR ASTHME PROFESSIONNEL PAR DES TESTS DE PROVOCATION BRONCHIQUE SPÉCIFIQUE ENTRE 1997 ET 2007

Labrecque M, G Moullec, L'archevêque J

Centre Asthme et travail; Centre de recherche de I'hôpital Sacré-Cour de Montréal, Montréal, QC

Les tests de provocation bronchique spécifique (TPS) en laboratoire ou en milieu de travail demeurent l'étalon-or de l'investigation d'Asthme Professionnel(AP). Nous présentons ici les caractéristiques et le diagnostic final des sujets investigués sur une période de 10 ans dans notre milieu. MÉTHODE : A l'aide d'une base de données des TPS comprenant des données complètes sur 1141 sujets investigués entre janvier 1997 et décembre 2007 nous avons pu établir la fréquence des différents diagnostics (Dx), les agents causaux retrouvés, les secteurs de travail plus fréquemment en cause ainsi que certaines caractéristiques homme/femme.

RÉSULTATS : La fréquence des différents Dx est la suivante : $21.5 \%$ (245) ont un AP confirmés par les TPS, 35.1\% ( 400) ont reçu le Dx. d'asthme personnel et (496) $43.5 \%$ un autre Dx. Pour chacune de ces catégories, il y a deux hommes en fréquence pour une femme, les hommes étant plus susceptible d'occuper un métier entraînant des symptômes respiratoires. En ce qui concerne le délai entre le début des symptômes et le début de l'investigation pour AP (mois) les femmes consultent en moyenne 10 à 12 mois plus tôt que les hommes $(34,7 \mathrm{~m}$ vs $44,9 \mathrm{~m} \mathrm{P}=.001)$.
DANS LA CATÉGORIE : Autre Dx, on retrouve en relation avec le travail ; 45 sujets avec Rhinite professionnelle (9.1\%), 12 sujets avec RADS (2.4\%), 7 sujets avec bronchite éosinophilique $(0,2 \%)$ et 3 cas d'Alvéolite Extrinsèque $(0,6 \%)$. Les autres sujets ont des conditions dites personnelles; 137 sujets avec hyperventilation (27.6\%) 263 sujets (53\%) avec conditions personnelles Rhinite ou sinusite chronique etc , 10 sujets avec toux chronique (2\%), 10 sujets avec MPOC (7\%). Pour les professions les plus fréquemment rencontrés chez l'homme; journalier, peintres-débosseleur, soudeur et chez la femme; journalière, technicienne, secrétaires, enseignantes, infirmières. Pour les agents plus souvent en cause chez l'homme; isocyanates, farines, produits chimiques variés et chez la femme ; produits chimiques, protéines variées, résines et colle.

CONCLUSION : Dans un centre de référence; Deux hommes pour une femme sont investigués pour AP, environ 1 patient sur 4 reçoit le Diagnostic d'AP après TPS. Tout Dx confondu : (1) Les femmes consultent en moyenne 10 à 12 mois avant les hommes en présence de symptômes respiratoires au travail.(2) Les professions les plus fréquentes chez l'homme ; journalier, peintre- débosseleur ,alors que chez la femme ; journalière enseignantes, secrétaires, technicienne, infirmières.(3) Les isocyanates et la farine sont les agents le plus souvent en cause chez l'homme alors que chez la femme on retrouve les produits chimiques et les protéines variées.

\section{7 \\ EXPOSITION DES TRAVAILLEURS QUÉBÉCOIS AUX FLUIDES DE COUPES DE MÉTAUX}

M Veillette, Y Gilbert, C Touzel, A Mériaux, J Lavoie, Y Cormier, $C$ Duchaine

Institut Universitaire de Cardiologie et de Pneumologie de Québec, Québec, QC

L'utilisation de fluides de coupe de métaux lors des opérations d'usinage du métal mène à la production d'aérosols et à l'exposition subséquente des travailleurs. Ces fluides sont souvent contaminés par des bactéries et les aérosols comportent des agents biologiques tels les endotoxines et/ou des microorganismes pouvant présenter un risque et mener à des affections telles l'alvéolite allergique extrinsèque. Plusieurs études ont aussi fait état de l'effet des brouillards d'huiles sur le système respiratoire des machinistes. Bien que la situation soit bien documentée, aucune donnée n'est disponible concernant la population québécoise de travailleurs de cette industrie. Nous avons visité 25 usines québécoises (44 sites d'usinage) et rencontré 208 travailleurs œuvrant dans cette sphère économique afin de décrire leur environnement de travail, leur état de santé et caractériser la composition des aérosols auxquels ils sont exposés. La biodiversité, les endotoxines, les brouillards d'huiles et les poussières totales furent évalués. Les travailleurs ont subi un questionnaire de santé respiratoire, une ponction de sang veineux pour la recherche d'anticorps et un test de fonction pulmonaire afin de décrire leur état respiratoire. À la lumière de nos résultats et contrairement à ce que la littérature présente, l'industrie de l'usinage au Québec ne représente pas un secteur d'activité à risque pour la santé respiratoire des travailleurs. De plus, les problèmes de santé relatés dans la littérature demeurent des évènements rares et causés par l'apparition fortuite d'une contamination massive et prévenus par l'instauration de mesures d'hygiène industrielle adéquates.

\section{8}

\section{MARQUEURS D'APOPTOSE DANS LE LAVAGE BRONCHOALVÉOLAIRE ET LA TRANSPLANTATION PULMONAIRE}

E O'Carroll, S Ptaszynski, S Al Mot, A Al Rabea, C Poirier, C Bergeron

CRCHUM, Montréal, QC

La bronchiolite oblitérante $(\mathrm{BO})$ est la première cause de mortalité chez les receveurs de greffe pulmonaire. La BO est caractérisée par une inflammation et un remodelage prédominant au niveau des bronchioles. Des facteurs paracrins dérivés de l'apoptose endothéliale, comme les débris de la protéolyse de la matrice extracellulaire (MEC) et le TGF-beta, sont reconnus pour leurs propriétés fibrotiques. Plusieurs stimuli, dont les épisodes de rejet aigu (RA) et les infections peuvent induire l'apoptose des cellules 
structurales bronchiolaires. Nous proposons que l'apoptose bronchiolaire déclenche la protéolyse de la MEC, ce qui favorise le développement de la $\mathrm{BO}$ par la stimulation de la prolifération, du remodelage et de l'inflammation. L'objectif de ce projet est de détecter la présence de marqueurs solubles d'apoptose, soit Fas, Fas-L, granzyme B (GZB) et perforine, dans les surnageants des lavages bronchoalvéolaires (LBA) de sujets transplantés et de les corréler avec les données cliniques pertinentes. Les LBA de vingt-cinq sujets de 1 à 240 semaines post-transplantation ont été analysés par la technique ELISA. Les marqueurs d'apoptose ont été positivement détecté dans les LBA. Tous ces marqueurs diminuent chez les patients atteints de BO et augmentent avec les épisodes de RA. Fas-L et GZB s'élèvent en présence d'infections virales. Nous avons démontré que l'apoptose survient avant le développement de la $\mathrm{BO}$ et est associé aux infections virales et aux épisodes de RA. Nous avons aussi optimisé un outil pour détecter les marqueurs précoces d'apoptose qui pourraient prédire le développement de la BO.

\section{9}

\section{ÉTUDE DU DÉFAUT DE RÉPARATION DE L'ÉPITHÉLIUM BRONCHIQUE FIBROSE KYSTIQUE}

NTN Trinh, É Maillé, A Privé, O Bardou, C Cagelais, E Brochiero Université de Montréal, département de Médecine et CR-CHUM Hôtel-Dieu, Montreal, QC

La défaillance respiratoire suite à la destruction de l'épithélium pulmonaire est la principale cause de mortalité en fibrose kystique (FK). Plusieurs stratégies ont été développées afin de corriger le défaut de base du canal CFTR et de tenter de contrôler les infections bactériennes et l'inflammation chroniques au niveau respiratoire, alors que, très peu sont consacrées à l'élaboration de thérapies visant à promouvoir la réparation des lésions épithéliales pulmonaires. Dans une étude précédente, nous avions constaté que les cellules bronchiques FK $(\mathrm{CuFi})$ présentaient un retard de réparation suite à des lésions, en comparaison avec les cellules normales (NuLi). Nous avons donc décidé d'étudier le défaut de réparation au niveau de l'épithélium bronchique FK en utilisant différents modèles cellulaires. À l'aide d'un modèle de plaies mécaniques, nous avons confirmé que la réparation dans les monocouches de cellules de bronches humaines FK était plus lente que celle des monocouches de cellules bronchiques issus de patients non-FK. De façon intéressante, nous avons aussi noté une amélioration de la réparation dans les lignées cellulaires corrigées avec du CFTR sauvage (S9 et CFBE-WT) comparativement aux lignées cellulaires FK (IB3 et CFBE deltaF508, respectivement). Cette étude va nous permettre de mieux comprendre les mécanismes de la réparation épithéliale et le retard de réparation des cellules FK afin de développer des stratégies promouvant la régénération l'épithélium pulmonaire en FK.

\section{0}

\section{RÔLE DE LA CYTOKINE THYMIC STROMAL LYMPHOPOIETIN (TSLP) DANS LA RÉPARATION DE L'ÉPITHÉLIUM BRONCHIQUE}

A Semlali ${ }^{1}$, E Jacques ${ }^{1}$, L Koussih ${ }^{2,3}$, A S Gounni ${ }^{3}$, J Chakir ${ }^{1}$

${ }^{1}$ Centre de recherche de l'Institut universitaire de cardiologie et de pneumologie du Québec, Québec, QC; ${ }^{2}$ CUSB; ${ }^{3}$ Department of Immunology, University of Manitoba, Winnipeg, MB

Thymic stromal lymphopoietin (TSLP) est une cytokine produite par plusieurs types cellulaires, notamment les cellules épithéliales, les cellules stromales et musculaires. Cette cytokine joue un rôle dans l'initiation de l'inflammation allergique des voies respiratoires.

OBJECTIVE: Déterminer l'effet de TSLP sur la prolifération et la réparation des cellules épithéliales isolées chez des sujets asthmatiques et sains. MÉTHODES: L'expression du récepteur de TSLP (TSLPR) a été réalisée par qPCR et immunobuvardage. La modulation de l'expression de TSLP par les cytokines TH2, ainsi que l'expression de IL-13 a été déterminée par qPCR, tandis que les protéines ont été mesurées par ELISA. La prolifération cellulaire a été évaluée par BrdU et par comptage cellulaire. La réparation de l'épithélium a été examinée par des blessures mécaniques de monocouches confluentes de cellules épithéliales des voies aériennes.

RÉSULTATS: TSLPR est exprimé par les cellules épithéliales sans aucune différence d'expression entre les sujets normaux et les sujets asthmatiques.
L'expression de TSLP est significativement plus élevée dans les cellules épithéliales isolées chez des sujets asthmatiques par rapport aux contrôles. Cette expression de TSLP est stimulée par les cytokines de type TH-2 en particulier IL-13. TSLP induit la prolifération et la réparation de l'épithélium bronchique, cet effet est inhibé lorsqu'on bloque l'IL-13. CONCLUSIONS: Nos résultats indiquent d'une part, que les cellules épithéliales expriment la TSLP et son récepteur, et d'autre part, cette TSLP joue un rôle important dans la prolifération et la réparation des cellules épithéliales bronchiques via la production de l'IL-13.

\section{1}

FTY720 MODULATES INFLAMMATION AND STRUCTURAL CHANGES ASSOCIATED WITH AIRWAY REMODELING

H Karmouty-Quintana, M Hassan, K Tsuchiya, S Siddiqui,

\section{J G Martin}

Meakins-Christie Laboratories, McGill University, Montreal, QC RÉSUMÉ: Sphingosine-1-phosphate (S1P), a bioactive lysophospholipid, is generated in the plasma membrane of many cells including mast cells and endothelial cells. Increased S1P levels have been reported in the bronchoalveolar lavage fluid (BALF) of asthmatics. FTY720, a synthetic analogue of S1P, is known to sequester lymphocytes away from sites of inflammation.

AIM: To investigate the effects of FTY720 in an experimental model of asthma.

METHODS: Ovalbumin (OA) sensitized rats were challenged 3 times with OA or vehicle with a 5 day interval between each challenge. FTY720 or vehicle treatment was performed $1 \mathrm{~h}$ prior to each OA challenge. BALF analyses for inflammatory markers were performed $48 \mathrm{~h}$ after the last challenge. Lung sections were stained for $\alpha$-smooth muscle actin, and CD3positive cells ( $T$ cells).

RESULTS: BALF analyses demonstrated that FTY720 was capable of inhibiting airways inflammation including eosinophilia, protein and IL-5 levels induced following multiple OA challenges. Histology demonstrated that FTY720 inhibited the OA induced increase in airway smooth muscle (ASM) mass. CD3 staining revealed an increase in T cells within ASM layers following OA that was reduced by FTY720.

CONCLUSIONS: These observations demonstrate that FTY720 is capable of inhibiting lymphocyte influx to the airways. The results suggest that the reduced presence of T cells, following FTY720, in the ASM layers results in a reduction in ASM mass as well as in cellular infiltration to the airways. These novel findings contribute to understanding the interrelationship between airway remodeling and immunity as well as proposing an alternative target for the treatment of asthma.

\section{2}

IMPACT DU TNF SUR LES MÉCANISMES DE RÉPARATION DE L'ÉPITHÉLIUM BRONCHIQUE FIBROSE KYSTIQUE Maillé $\mathrm{E}^{1}$, Trinh $\mathrm{NTN}^{2}$, Privé $\mathrm{A}^{1}$, Bissonnette $\mathrm{E}^{2}$, Brochiero $\mathrm{E}^{1}$ ${ }^{1}$ Département de médecine de I'Université de Montréal, Montréal; ${ }^{2}$ Département de médicine de l'Université Laval, Québec, QC Chez les patients fibrose kystique (FK), les infections bactériennes et l'inflammation causent une destruction progressive de l'épithélium pulmonaire entraînant une détresse respiratoire. Cependant, on ignore quel est leur impact sur les processus de réparation suite à ces lésions. Nous avons montré que la réparation de l'épithélium bronchique $\mathrm{FK}(\mathrm{CuFi})$ était retardée par rapport à l'épithélium bronchique sain $(\mathrm{NuLi})$. Ce retard est accompagné d'une altération de la réponse à l'EGF et de la fonction des canaux $\mathrm{K}^{+}$, deux éléments cruciaux à la réparation épithéliale. Nous avons donc étudié l'impact de l'inflammation, plus particulièrement du TNF, sur les mécanismes de réparation (avec un modèle de plaies mécaniques) ainsi que sur la réponse à l'EGF et la fonction des canaux $\mathrm{K}^{+}$. Nous avons observé que l'exposition au TNF (40ng/ml) augmente la réparation des NuLi (140\%) et des CuFi (170\%) diminuant ainsi le retard de réparation des CuFi. Un traitement chronique au TNF accentue son effet stimulateur. De plus, la stimulation de la réparation par le TNF est abolie en présence d'inhibiteurs des récepteurs EGF et d'anticorps anti-EGF titrant l'EGF sécrété par les cellules. Nos résultats montrent aussi que la présence 
d'inhibiteurs des canaux $\mathrm{K}^{+}$abolit l'effet du TNF sur la réparation tandis que le TNF stimule les courants $\mathrm{K}+$. Il semble donc exister une relation entre l'inflammation, la voie EGFR et les canaux $\mathrm{K}^{+}$. Cette étude permettra de mieux comprendre le rôle de l'inflammation dans la réparation de l'épithélium pulmonaire et à long terme de mieux adapter les thérapies visant à stabiliser les patients FK.

\section{3}

\section{THE EFFECTS OF THE LOW MOLECULAR WEIGHT HEPARIN ON NON SMALL CELL LUNG CANCER CELLS IN VITRO}

Abu Arab W, Echavé V , Sirois M, Kotb R, Rousseau É Department of Physiology and Biophysics, Division of Thoracic Surgery, Division of Hematology and Oncology, Faculty of Medicine and Health Sciences, Sherbrooke University, Sherbrooke, QC

Local recurrences and distant metastases after surgical resection of Non Small Cell Lung Cancer (NSCLC) are the main causes of low survival rates. The Low Molecular Weight Heparin (LMWH) was proven to have a positive impact on patients' survival with some types of cancers which were partially attributed to the anticoagulant mechanisms. Mestastatic process includes many steps (cell proliferation, migration, adhesion, and invasion). The goal of this study was to test whether LMWH has an effect or not on metastatic process of NSCLC in vitro.

A predefined number of A549 cells $\left(1 \times 10^{4}\right.$ cell/well in 6 well plates $)$ were cultured in vitro with different concentrations of Enoxaparin $(0,1,5,10$, 20 , and $30 \mathrm{U} / \mathrm{ml}$ ). Cell counting was performed at 24, 48, and 72 hours. Detection of c-Myc protein production which is involved in the tumour genesis was performed by electrophoresis and Western Blot techniques. The data collected was analysed using Student-t test.

RESULTS: At 24 hours, the cell number was shown to be decreased for cultures at different concentrations of Enoxaparin (3, 3.75, 5, 4.25, and $4.75 \times 10^{4} \mathrm{cell} /$ well for the Enoxaparin concentrations of 1, 5, 10, 20 and $30 \mathrm{U} / \mathrm{ml}$, respectively) compared to control wells $\left(5.75 \times 10^{4}\right.$ cell $/$ well $)$. This decrease reached statistical significance for the higher Enoxaparin concentrations at 48 hours $\left(9.25,11\right.$, and $11.25 \times 10^{4}$ cell/well and $p$-value of $0.03,0.008$, and 0.01 for 10,20 , and $30 \mathrm{U} / \mathrm{ml}$, respectively). The optical density of c-Myc bands revealed decreased production of the c-Myc protein proportionately with the increased concentration of Enoxaparin.
Hence, Enoxaparin seems to have a direct suppressor effect on NSCLC A549 cell line proliferation and production of c-Myc in vitro. These results should be further investigated to characterize the possible anti-neoplastic effects of Enoxaparin in patients with NSCLC.

\section{4}

\section{ANTIGEN-SPECIFIC CD4 ${ }^{+}$T CELLS DRIVE AIRWAY SMOOTH MUSCLE PROLIFERATION THROUGH THE EPIDERMAL GROWTH FACTOR RECEPTOR}

S Al Heialy, B Tolloczko, K Tsuchiya, S Siddiqui, D Ramos-Barbon, JG Martin

Meakins-Christie Laboratories, Dept of Medicine, McGill University, Montreal, QC

Airway smooth muscle (ASM) hyperplasia is an important feature of remodeling in asthma associated with the severity of the disease. Previous studies have shown that antigen-specific $\mathrm{CD} 4{ }^{+} \mathrm{T}$ cells induce ASM proliferation through direct cell-cell interaction. In vitro studies have shown that $\mathrm{CD}^{+} \mathrm{T}$ cells express amphiregulin (Areg), an epidermal growth factor receptor (EGFR) ligand. ASM cells from asthmatic patients have shown an upregulation of EGFR. We hypothesized that $\mathrm{CD}^{+} \mathrm{T}$ cells induce ASM proliferation through the EGFR in vitro. Lymph nodes cells from ovalbumin (OVA)-sensitized rats were cultured in OVA. ASM cells (ASMC) were cultured from trachea of OVA-sensitized rats. The ASMC were seeded to $85 \%$ confluency and cell cycle-arrested for $72 \mathrm{~h}$. OVAstimulated $\mathrm{CD}^{+} \mathrm{T}$ cells were then isolated by immunomagnetic negative selection and co-cultured in direct contact with ASMC for 48h. AG1478, an EGFR blocker, was added. EGFR phosphorylation was confirmed by immunofluorescence. ASMC proliferation was assessed by flow cytometry. Real-time polymerase chain reaction was used to assess mRNA expression of the EGFR ligands in $\mathrm{CD}^{+} \mathrm{T}$ cells before and after co-culture of the cells with ASMC. Flow cytometric analysis showed that antigen-specific $\mathrm{CD} 4^{+}$ $\mathrm{T}$ cells induce ASMC proliferation $(56.43 \pm 6.31 \%)$. In the presence of AG1478, ASMC proliferation was inhibited and restored to baseline (32.71 $\pm 3.62 \%) . \mathrm{CD}^{+} \mathrm{T}$ cells differentially express Areg, epidermal growth factor (EGF), heparin-binding EGF and transforming growth factor- $\alpha$ before and after co-culture with ASMC. Co-culture led to EGFR phosphorylation which was inhibited by AG1478. These findings implicate EGFR in airway remodeling.

\section{AUTHOR INDEX TO ABSTRACTS}

A

Abu Arab W..................63

Albadine R . . . . . . . . . . . . . . $10,11,19$

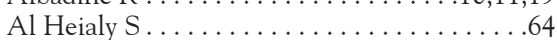

Al Mot S.................. 13,58

Al Rabea A . . . . . . . . . . . . . . . . .

Allakhverdi Z . . . . . . . . . . . . . . . . . .

Al-Ramli W . . . . . . . . . . . . . . 8

Angers I. . . . . . . . . . . . . . . . . . 39

Arnold D. . . . . . . . . . . . . . . . . . 49

Arnold DL. . . . . . . . . . . . . . . . . . 54

Avoine $O \ldots \ldots \ldots \ldots \ldots \ldots . \ldots \ldots, 46,48$

\section{B}

Bairam A....................... 18

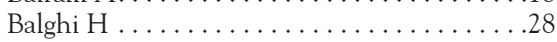

Bardou O. . . . . . . . . . . . . . . . 29,59

Bar-Or A . . . . . . . . . . . . . . . 49,54

Bates $G \ldots \ldots \ldots \ldots \ldots \ldots \ldots \ldots \ldots \ldots$. . . . . . . . . . .

Beaudry B . . . . . . . . . . . . . . . . . . 19

Beaulieu A . . . . . . . . . . . . . . . . 19,46,48

Beck J ....................... 47

Bellemare F.....................44

Benedetti A. . . . . . . . . . . . . 49,54

Bergeron C . . . . . . . . . . . . . . 13,21,33,58

Bernier A . . . . . . . . . . . . . . . . .23

Berthiaume $Y \ldots \ldots \ldots \ldots \ldots \ldots \ldots .29,32$

Bérubé J.................... 16,35
Bisonnette É . . . . . . ...................62

Bissonnette EY . . . . . . . . . . . . . . 3,31

Blais Lecours P . . . . . . . . . . . . . . . . . .41

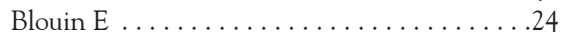

Bordessoule A . . . . . . . . . . . . . . . . 47

Bossé D . . . . . . . . . . . . . . . . 19,48

Bougault V ..........................24

Boulet L-P................... 24,43

Boutin I. . . . . . . . . . . . . . . . . . . .25

Brisebois S. . . . . . . . . . . . . . .23

Brochiero E . . . . . . . . . . . . . . . . 29,59,62

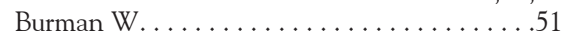

\section{$\mathrm{C}$}

Cagelais C......................59

Caron M-A . . . . . . . . . . . . . . . . . .22

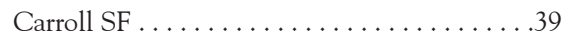

Castonguay-Vanier J . . . . . . . . . . . . . . . . 40

Chakir J........................ 1,8,60

Champagne K......................25

Charette SJ . . . . . . . . . . . . . . . . . . . 40

Chouinard F . . . . . . . . . . . . . . 12,14

Colombini L . . . . . . . . . . . . . . . . . 45

Comeau MR . . . . . . . . . . . . . . . . 7

Cormier G. . . . . . . . . . . . . . . . . 30

Cormier Y . . . . . . . . . . . . . . 38,41,42,57

Côté I . . . . . . . . . . . . . . . . . . . . 49
D

D'Anjou G .......................445

Da Costa D . . . . . . . . . . . . . . . . . . 49,54

Dagenais A . . . . . . . . . . . . . . 29,32

Daigle F..................... 40

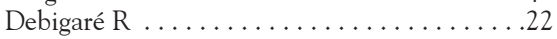

Dekimpe V . . . . . . . . . . . . . . . . . . . .40

Delespesse G.....................

Denburg JA . . . . . . . . . . . . . . . . .7

Des Cormiers A . ................... 43

Desrosier M . . . . . . . . . . . . . . . . . .

Déziel E...........................40

Donnelly DF ......................

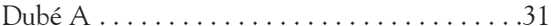

Dubois Y ........................21

Duchaine C. . . . . . . . . . . . . . . . . . 41,42,57

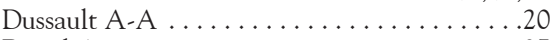

Duval A. .......................

$\mathrm{E}$

Echave V....................10,11,63

Eddington A . . . . . . . . . . . . . . . . . . 47,50

Eidelman D . . . . . . . . . . . . . . . . . . 17

Endam LM $\ldots \ldots \ldots \ldots \ldots \ldots \ldots \ldots \ldots \ldots \ldots$

Evagelidis A ......................28

$\mathrm{F}$

Fairbank NJ. .................... 9

Ferland C . . . . . . . . . . . . . . . . . . 14 
Ferraro $\mathrm{P} \ldots \ldots \ldots \ldots \ldots \ldots \ldots \ldots \ldots \ldots \ldots$

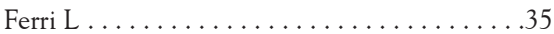

Filion G. . . . . . . . . . . . . . . . . . 40

Fixman E..................... 6,9

Flamand $\mathrm{N} \ldots \ldots \ldots \ldots \ldots \ldots \ldots \ldots$. 12,14

Forster R ....................41

Fortin S . . . . . . . . . . . . . . . . 10

Frenkiel S . . . . . . . . . . . . . . . . .8

Frigola $G \ldots \ldots \ldots \ldots \ldots \ldots \ldots \ldots \ldots$

G

Gautrin D . . . . . . . . . . . . . . . . . . 53

Gauvin F..................... 50

Gauvreau GM....................

Ghezzo H. . . . . . . . . . . . . . . . . . . . . . . .55

Gilbert Y....................57

Girard M..........................

Goepp, J .......................28

Gounni AS . . . . . . . . . . . . . . . . 60

Grandvaux N . . .....................

Groleau MC .......................... 40

Grütter P................... 5

$\mathrm{H}$

Hamid Q. . . . . . . . . . . . . . . . 8,17,35

Hanrahan JW . . . . . . . . . . . . . . . . . .28

Harries AD . . . . . . . . . . . . . . . . . 51

Hassan M . . . . . . . . . . . . . . . 15,61

Hebert M-J . . . . . . . . . . . . . . . . . . 33

Houle F............................ 35

Howie KJ. . . . . . . . . . . . . . . . . 7

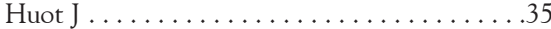

Israël-Assayag $\mathrm{E} \ldots \ldots \ldots \ldots \ldots \ldots \ldots . \ldots . \ldots 38$

$\mathrm{J}$

Jacques E....................... 1,60

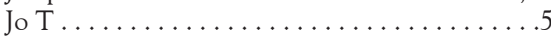

Jobin $\mathrm{V} \ldots \ldots \ldots \ldots \ldots \ldots \ldots \ldots \ldots$

Joseph V . . . . . . . . . . . . . . . . . . 18

Jouvet P. . . . . . . . . . . . . . . 47,50

K

Kachmar L. . . . . . . . . . . . . . . . . . . . . .9

Kaminska M . . . . . . . . . . . . . . . . . 44,49,54

Karmouty-Quintana H . . . . . . . . . . . . . . . . .61

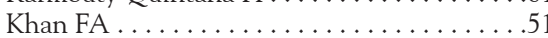

Kimoff RJ . . . . . . . . . . . . . . . . . . 25,49,54

Kinyanjui M . . . . . . . . . . . . . . . . . . .6

Kotb R. . . . . . . . . . . . . . . . . . .63

Koussih L. . . . . . . . . . . . . . . . . . . .60

L

Laberge S. ............... 45

Labrecque $\mathrm{M} \ldots \ldots \ldots \ldots \ldots \ldots \ldots \ldots \ldots . \ldots \ldots 5,56$

Lacroix J . . . . . . . . . . . . . . . . . . . . .50

Lafferty EI . . . . . . . . . . . . . . . . . . . . 39

Lamarche MG. . . . . . . . . . . . . . . . . 40

Lambert MH....................27

Landry J. . . . . . . . . . . . . . . . . . . . . . . . 52

Langlois A......................... 12

Lapierre JG . . . . . . . . . . . . . . . . . . . . .45

Lapierre Y . . . . . . . . . . . . . . . . . . 49,54

Laprise C. . . . . . . . . . . . . . . 27,31
L'Archevêque J

Lauzon A-M .
Lauzon-Jose JF

Lavigne $\mathrm{F}$.

Lavigne L

Laviolette M . .

Lavoie J....

Lavoie JP................... 4,26

Lavoie K . . . . . . . . . . . . . . . . . . . . 53

Lavoie-Lamoureux A . . . ......... 4,26

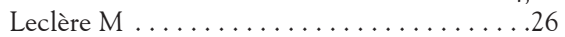

Lefebvre JS . . . . . . . . . . . . . . . . . . . .14

Lemay J . . . . . . . . . . . . . . . . . . . 20

Lemieux S........................ 32

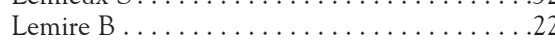

Létourneau $\mathrm{V} \ldots \ldots \ldots \ldots \ldots \ldots \ldots . . \ldots 42$

Lévesque M. . . . . . . . . . . . . . . . . . .55

Loubaki L . . . . . . . . . . . . . . . . . 1

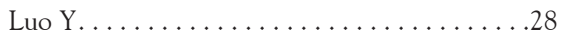

\section{$\mathrm{M}$}

Madore A-M . .......................... 27,3

Maillé É. ................... 5 59,62

Malo JL . . . . . . . . . . . . . . . . . . . 53,55

Maltais F....................22

Marquis F . . . . . . . . . . . . . . . . . .45

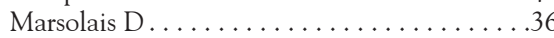

Martel A . . . . . . . . . . . . . . . . . . . . 37

Martin, JG. . . . . . . . . . . . . 5,15,26,61,64

Massé D..........................42

Mathieu A. ...................... .44

Mayer P................... . . 44

McGovern T. . . . . . . . . . . . . . . ...15

Menzies D . . . . . . . . . . . . . . . 51,52

Mériaux, A . . . . . . . . . . . . . 42,57

Micheau P. . . . . . . . . . . . . . . . . . 19,46,48

Minion J . . . . . . . . . . . . . . . . . .51

Mogas AK . . . . . . . . . . . . . . . . . 8

Montpetit A . . . . . . . . . . . . . . . . . . .44

Morin C . . . . . . . . . . . . . . 10,11

Morisset J . . . . . . . . . . . . . . . . . .21

Morisson F. . . . . . . . . . . . . . . . . . 44

Moullec G. . . . . . . . . . . . . 53,56

$\mathrm{N}$

Nadigel J . . . . . . . . . . . . . . . . . . . . . 17

Nakada E. . . . . . . . . . . . . . . . 6, 6

Nattagh L . . . . . . . . . . . . . . . . . . . . 16

Nguyen TTD. . . . . . . . . . . . . . . . . 45

Niane $\mathrm{LM} \ldots \ldots \ldots \ldots \ldots \ldots \ldots$

$\mathrm{O}$

O'Carroll E . . . . . . . . . . . . . 13,21,58

Olivenstein R . . . . . . . . . . . . . . . . 35

\section{$\mathbf{P}$}

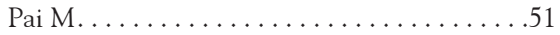

Paré M-E.......................22

Payen V........................50

Plante S. . . . . . . . . . . . . . . . . . . . . .

Poirier C . . . . . . . . . . . . . . . 13,58

Praud J-P . . . . . . . . . . . . . . . 19,23, 48

Préfontaine D . . . . . . . . . . . . . . . . 8,17

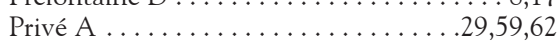

Provost P. . ....................... 30

Provost V . . . . . . . . . . . . . . . . 12

Ptaszinski S . . . . . . . . . . . . . . . 13,33,58

Q

Qureshi ST ...........

Ramos-Barbon D. . . . . . . . . . . . . . . . . . .64

Risse PA .................. 5,15

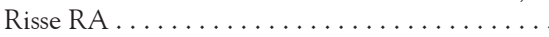

Robay A .................... 21,33

Robert R . . . . . . . . . . . . . . . . 19,28,46

Robinson A. .................. . 49,54

Rola-Pleszczynski M . . . . . . . . . . . . . . 12

Roman HN . . . . . . . . . . . . . . . . . . . . 34

Rousseau É . . . . . . . . . . . . . 10,11,63

Rousseau S . . . . . . . . . . . . . . . . . 16,35

Roussel L................... . 16,35

Royce S.......................51

\section{$\mathrm{S}$}

Samson $\mathrm{N} \ldots \ldots \ldots \ldots \ldots \ldots \ldots \ldots \ldots . . \ldots \ldots$

Santschi M . . . . . . . . . . . . . . . . . . . 50

Schwartzman K.................25,49,54

Semlali A .................. 8, 8, 60

Senouvo FY. . . . . . . . . . . . . . . . 11

Sériès F . . . . . . . . . . . . . . . . 20

Shan J ........................6

Siddiqui $S \ldots \ldots \ldots \ldots \ldots \ldots \ldots \ldots . \ldots . \ldots . \ldots 61,64$

Sirois M. . . . . . . . . . . . . 10,11,63

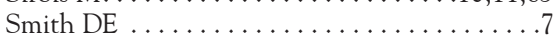

Sobieszek A..........................34

Suarez F. . . . . . . . . . . . . . . .

\section{$\mathrm{T}$}

Tan SL...........................25

Thériault M-E. . . . . . . . . . . . . . 22

Thomas DY ......................28

Tolloczko B . . . . . . . . . . . . . . . . . .64

Touzel C . . . . . . . . . . . . . . . . . . . .57

Toy D.......................

Tremblay K . . . . . . . . . . . . . . . .27

Tremblay Y . . . . . . . . . . . . . . . 30

Trinh NTN . . . . . . . . . . . . . . . . . . . 29,59,62

Trojan DA. . . . . . . . . . . . . . . . . 49,54

Tsuchiya K. . . . . . . . . . . . . . . . . 15,61,64

Turmel J. . . . . . . . . . . . . . . . . . . 24

Turmel V................... 3,31

V

Veillette M . . . . . . . . . . . . . . . 41,57

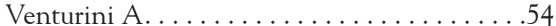

Vial L.......................... . . . . . .

Vidal SM. . . . . . . . . . . . . . . . . . . .39

Voisin $G \ldots \ldots \ldots \ldots \ldots \ldots \ldots \ldots \ldots \ldots$

W

Walti H..................... 19,46,48

Weiss D . . . . . . . . . . . . . . .49

$\mathrm{Y}$
Yoboua $\mathrm{F} \ldots \ldots \ldots \ldots \ldots \ldots \ldots \ldots \ldots$

Zitouni NB ................. 


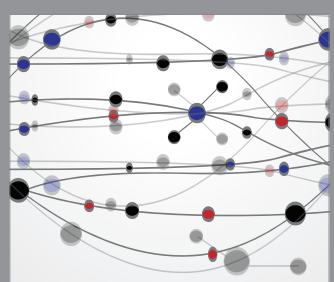

The Scientific World Journal
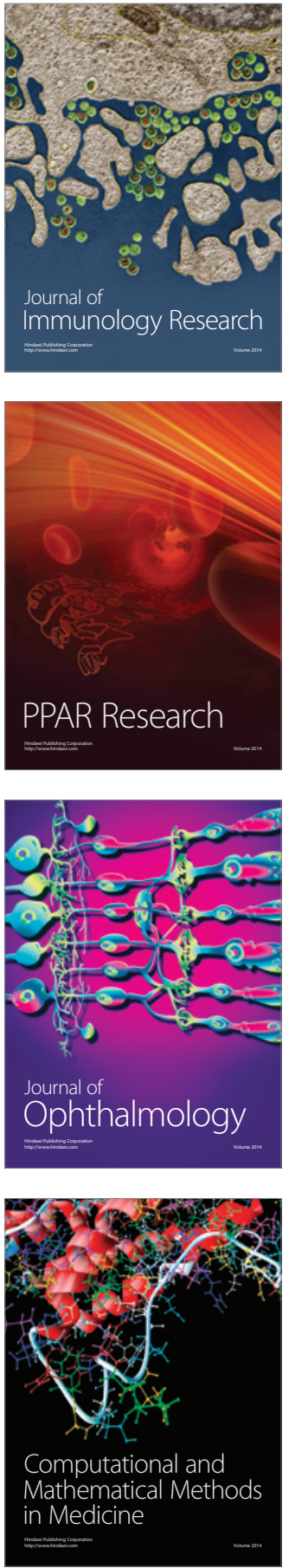

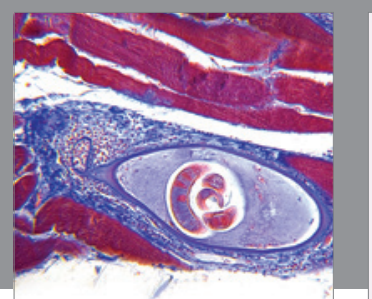

Gastroenterology Research and Practice

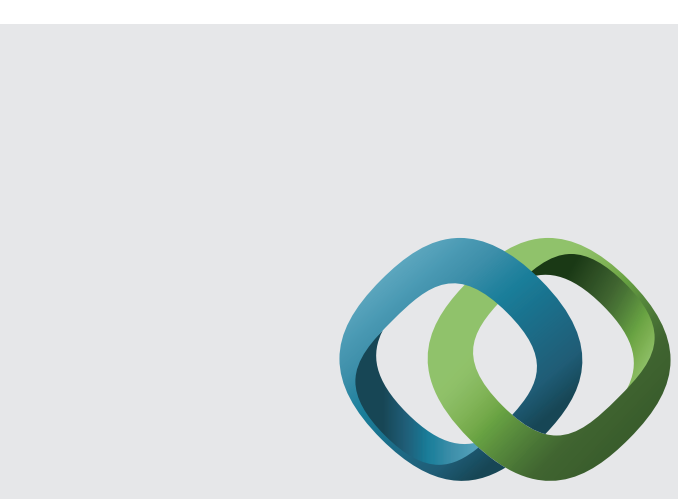

\section{Hindawi}

Submit your manuscripts at

http://www.hindawi.com
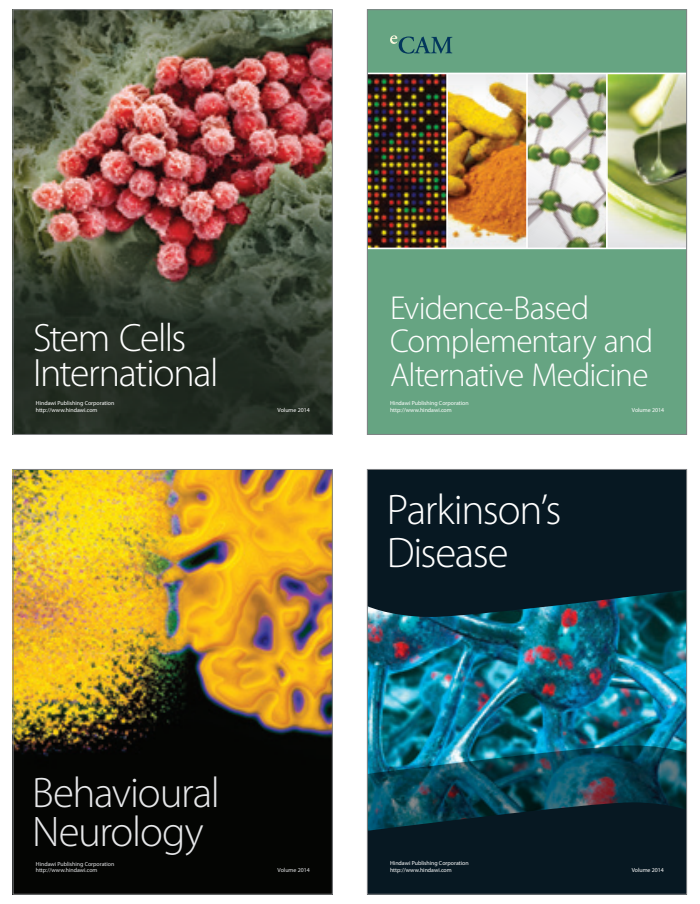
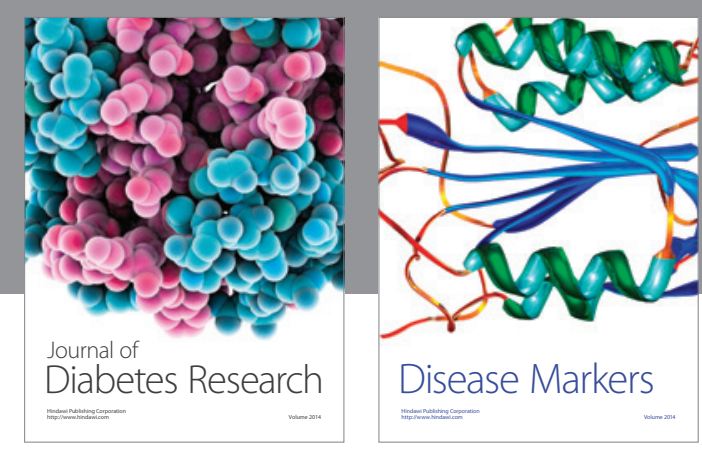

Disease Markers
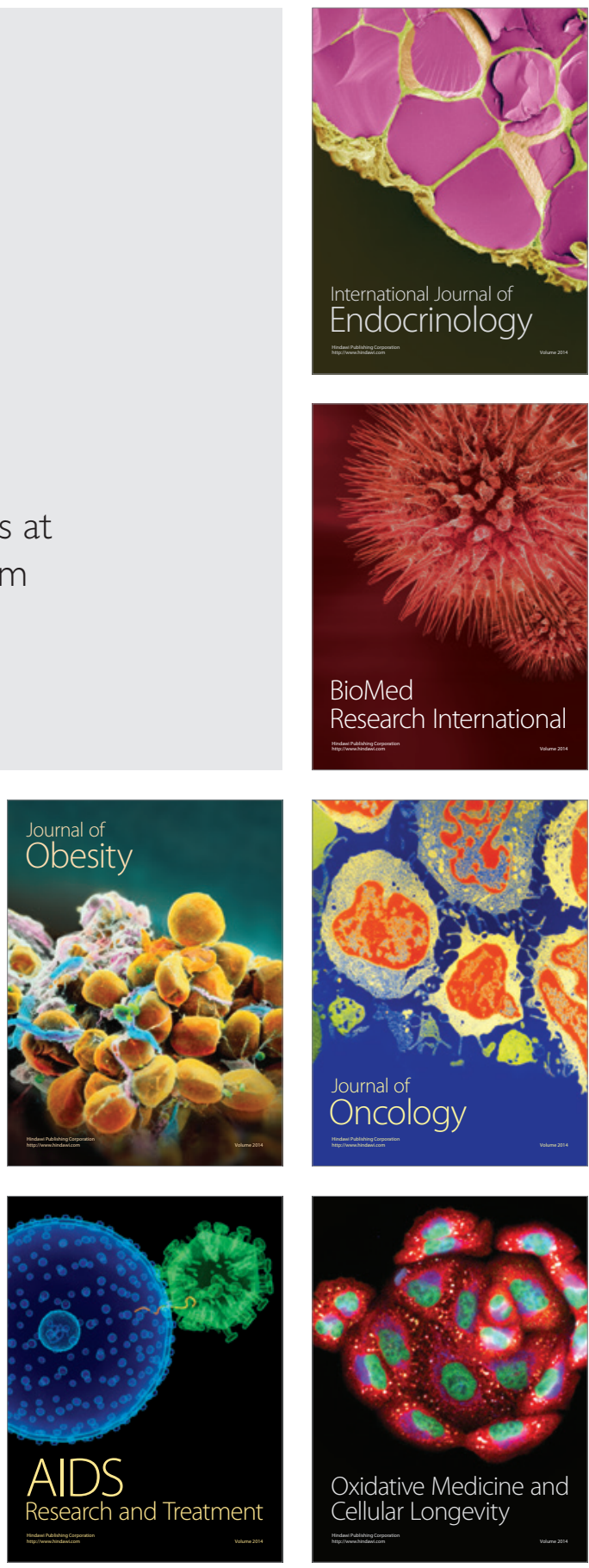